\title{
Cheminformatic scrutiny of some heterocyclic compounds for their corrosion protective capability
}

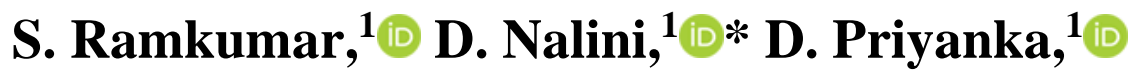 \\ M.A. Qurashi ${ }^{2}{ }^{\oplus}$ and D.S. Chauhan ${ }^{3}(\mathbb{D}$ \\ ${ }^{1}$ Department of Chemistry, PSGR Krishnammal College for Women, Coimbatore - \\ 641004, Tamil Nadu, India \\ ${ }^{2}$ Interdisciplinary Research Center for Advanced Materials, King Fahd University of \\ Petroleum and Minerals, Dhahran 31261, Saudi Arabia \\ ${ }^{3}$ Center of Research Excellence in Desalination and Water Treatment, Research Institute, \\ King Fahd University of Petroleum and Minerals, Dhahran 31261, Saudi Arabia \\ *E-mail: nalini@psgrkcw.ac.in
}

\begin{abstract}
Over the last two decades, molecular modellings are capable of accurately predicting structures, energetics, reactivity, and other properties of molecules. Computational chemistry plays an important role in enabling chemists to: (i) explain and rationalize known chemistry of corrosion inhibitors and (ii) explore new or unknown chemicals applicable as corrosion inhibitors. In contrast to the traditional techniques of identifying and synthesizing new corrosion inhibitors in the wet lab, a prior dry-lab process is suggested by using cheminformatics tools. Once a correlation between the structure and activity or property is found, any number of compounds can be readily screened employing computational methodology. In the present work, the inhibitive performance of three important classes of heterocyclic compounds namely dithiazolidine, thioamidine, and thiourea derivatives have been calculated using quantum chemical methods. The three selected heterocyclic series contains nitrogen and sulphur in their chemical framework that were expected to be the main electron rich centres which act as the adsorption sites on the metal surface. The presence of aromatic ring together with electron donating substituents such as methyl and methoxy were found to enhance the adsorption characteristics of the studied heterocyclic systems. The global reactivity parameters and the local selectivity adsorption centres in each of the studied system were analyzed using theoretical parameters.
\end{abstract}

Received: May 19, 2021. Published: December 27, 2021

doi: $\underline{10.17675 / 2305-6894-2021-10-4-26}$

Keywords: computational study, heterocyclic compounds, corrosion inhibition, DFT, Fukui indices.

\section{Introduction}

Quantum chemical methods have proven to be very useful in determining the molecular structure as well as elucidating the electronic structure and reactivity [1]. The concept of assessing the efficiency of a corrosion inhibitor with the help of computational chemistry is 
to search for compounds with desired properties using chemical intuition [2, 3]. There are two broad areas within computational chemistry related to the structure of molecules and their reactivity: "Molecular Mechanics and Electronic Structure Theory".

Molecular mechanics - Molecular mechanics stimulations use the law of classical physics to predict the structures and properties of molecules, which is characterized by a particular force field. A force field has three components - a set of equations defining how the potential energy of a molecule varies with the locations of its atoms, a series of atom type defining the characteristics of an element within a specific chemical content, and one or more parameter set the fit the equation set and atom type to the experimental data.

Electronic structure theory-Electronic structure methods use the laws of quantum mechanics rather than classical physics as their basis. Quantum mechanics states that the energy and other related properties of a molecule are obtained by solving the timeindependent Schrödinger wave equation [4]. The electronic structure method is characterized by its various mathematical approximations to its solution.

\section{Theory of Quantum Chemistry}

The theoretical foundation for computational chemistry is the time-independent Schrödinger wave equation:

$$
\check{\mathrm{H}} \Psi=E \Psi
$$

$\Psi$ is the wave function. $\breve{H}$ is the Hamiltonian operator and is associated with observable energy. $E$ is the total energy of the system [5]. The Hamiltonian, $\breve{\mathrm{H}}$, is an operator. It contains all the terms that contribute to the energy of a system:

$$
H^{\wedge}=T^{\wedge}+V^{\wedge}
$$

Which describes a system consisting of nuclei and electrons. Born-Oppenheimer approximation is used to arrive at the solution to the above equation.

\section{Method of Calculation}

\section{Model Chemistry}

The Schrödinger wave equation can be approximated much more closely for small systems than for large ones. However, using different levels of theory for different size molecules makes comparing results among systems unreliable [6-8]. The implementation of such a theoretical model is termed as "Theoretical Model Chemistry" or "Model Chemistry". Model chemistries are characterized by the combination of theoretical procedure and basis set [9].

Basis Set-A Basis Set is a mathematical representation of the molecular orbitals within a molecule. The basis set can be interpreted as restricting each electron to a particular region of space. A larger basis set imposes fewer constraints on electrons and more accurately approximate exact molecular orbitals. 
Methods-There exists a hierarchy of procedures corresponding to different approximation methods commonly referred to as different levels of theory namely, Hartree-Fock self-consistent field, Beck-style 3-parameter Density Functional Theory (using the Lee-Yang-Parr correlation functional), $2^{\text {nd }}$ order Moller-Plesset Perturbation Theory, $2^{\text {nd }}$ order Moller-Plesset Perturbation Theory (including singlet, doublet, triplet and quadruples by default), Quadratic CI (single, doubles and triples).

Many researchers report that the inhibition effect mainly depends on some physicochemical and electronic properties of the organic inhibitor which relate to its functional groups, steric effects, electronic density of donor atoms, and orbital character of donating electrons, and so on $[10,11]$. The use of theoretical parameters presents two main advantages: firstly, the compounds and their various fragments and substituents can be directly characterized based on their molecular structure only; and secondly, the proposed mechanism of action can be directly accounted for in terms of the chemical reactivity of the compounds under study [12]. The work aims to study the inhibitive properties of three groups of heterocyclic compounds namely, dithiazolidine, thioamidine, and thiourea derivatives using quantum chemical methods.

Theoretical calculations were carried out using Restricted Density function level using the Becke's Three Parameter Hybrid Functional using the Lee-Yang-Parr correlation functional theory (B3LYP) method with the basis set 6-31 G (d,p) in the GAUSSIAN 09 [13] program package implemented on an Intel Pentium core i5 $166 \mathrm{MHz}$ computer. Initial estimates for all the geometries of all the structures were obtained by GAUSS VIEW [14] program followed by full optimization of all the geometric parameters (bond length, bond order, and dihedral angle) without any symmetry constraints using the DFT method.

Tang et al. synthesized three thiadiazole derivatives as new corrosion inhibitors for copper substrates in $0.5 \mathrm{M} \mathrm{H}_{2} \mathrm{SO}_{4}$ solution. It was revealed that the inhibition efficiency increases with an increase in inhibitors concentration and depends on the substituents on thiadiazole rings [49]. The corrosion inhibition by 2-amino-4-(4-methoxyphenyl)-thiazole on the mild steel substrates were investigated by Gong et al. The inhibition efficiency was $95 \%$ in $0.5 \mathrm{M} \mathrm{H}_{2} \mathrm{SO}_{4}$ solution which was mainly due to the electron donating methoxy group that endowed superior adsorption tendency of the molecule on steel surface [50]. Fouda et al. reported that five Phenylthiourea derivatives as corrosion inhibitors for carbon steel in $2 \mathrm{M}$ $\mathrm{HCl}$ solution. All the derivatives showed an increase in corrosion efficiency with increase in the concentration of the inhibitors [56].

Corrosion inhibitors, particularly the compounds containing aromatic ring and heteroatoms, are economic, thus they are considered as the most potential agents against corrosion mechanisms. These inhibitors have the ability to form dense films on the surface of mild steel owing to the role of filling electrons in heteroatoms to the vacant orbitals on the iron surface. Hence, we have intended to study compounds with aromatic rings containing $\mathrm{N}$ and $\mathrm{S}$ atoms in their structures. 


\section{Results and Discussion}

The studied compounds (Table 1) were grouped into three series according to their behavior and structure in order to make a systematic study between their structure and inhibitive properties.

In each series, the parent compound and its two derivatives namely methyl and methoxy were compared for their inhibitive behavior. The parent compound, methyl, and methoxy derivatives were designated with the abbreviation $\mathbf{a}, \mathbf{b}$ and $\mathbf{c}$, respectively. The derivatives were selected due to the enhanced $+I$ effect. The methyl and methoxy substituents at the $p$ position of the aromatic ring act as electron donating groups [49-55].

\subsection{Structural property of the heterocyclic systems}

Figure 1 reports the lowest energy conformer corresponding to each structure (optimized geometry). The lowest energy conformer with the bond lengths of the different bonds in the studied compounds as given in Tables $2-4$ and are discussed as follows: The $\mathrm{C}-\mathrm{C}$ bond lengths $(\AA)$ of the aromatic ring are in the range 1.39-1.41 for all the studied compounds. These ranges are comparable to the range of the calculated and experimental bond lengths in isolated benzene rings [14].

The longest bond lengths correspond to the $\mathrm{C}-\mathrm{S}-\mathrm{C}$ bond in dithiazolidine derivatives $(2.857 \AA)$. These bonds also correspond to the weakest bonds (lowest values of the bond order) in the studied systems. The $\mathrm{C}-\mathrm{N}$ bond lengths are relatively closer to the $\mathrm{C}-\mathrm{C}$ bond length while the $\mathrm{C}=\mathrm{N}$ bond is the shortest. The bond length of $\mathrm{C}-\mathrm{N}$ is shorter than the general $\mathrm{C}-\mathrm{N}$ single bond $(1.470 \AA)$ [15]. The $\mathrm{C}=\mathrm{N}$ bond length also has the highest bond order value and therefore it is the strongest. Similarly, in the thioamidine and thiourea series longest bond lengths correspond to the $\mathrm{N}-\mathrm{S}-\mathrm{N}$ derivatives $(2.326-2.857 \AA$ ). These bonds also correspond to the weakest bonds (lowest values of the bond order) in the studied systems $[16,17]$.

A positive dihedral angle indicates that both the groups in the studied plane are upwardly inclined to the lateral axis and when the groups are downwardly inclined it is represented by a negative dihedral angle as evidenced from Tables $2-4$. This also proves the non-planarity in the dithiazolidine and thioamidine series, whereas the thiourea series is planar in structure. 
Table 1. Inhibitor system used in the current investigation.

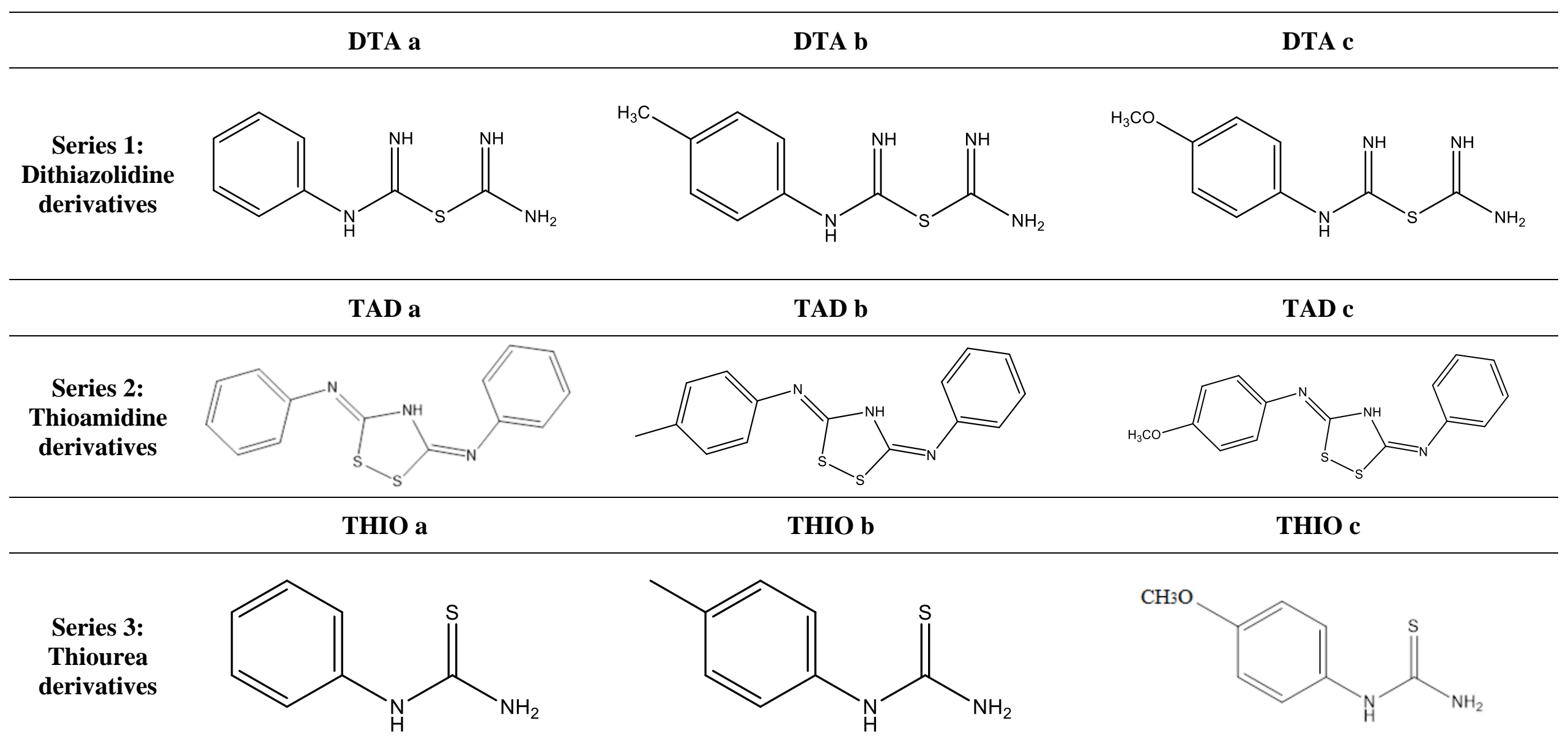


Table 2. Structural parameters for the dithiazolidine series.

\begin{tabular}{|c|c|c|c|c|c|c|c|c|c|c|c|}
\hline \multicolumn{4}{|c|}{ DTA a } & \multicolumn{4}{|c|}{ DTA b } & \multicolumn{4}{|c|}{ DTA c } \\
\hline Symbol & $\begin{array}{c}\text { Bond } \\
\text { Length }\end{array}$ & $\begin{array}{l}\text { Bond } \\
\text { Angle }\end{array}$ & $\begin{array}{c}\text { Dihedral } \\
\text { Angle }\end{array}$ & Symbol & $\begin{array}{l}\text { Bond } \\
\text { Length }\end{array}$ & $\begin{array}{l}\text { Bond } \\
\text { Angle }\end{array}$ & $\begin{array}{c}\text { Dihedral } \\
\text { Angle }\end{array}$ & Symbol & $\begin{array}{l}\text { Bond } \\
\text { Length }\end{array}$ & $\begin{array}{l}\text { Bond } \\
\text { Angle }\end{array}$ & $\begin{array}{c}\text { Dihedral } \\
\text { Angle }\end{array}$ \\
\hline $2 \mathrm{C}$ & 1.3784 & - & - & $2 \mathrm{C}$ & 1.3925 & - & - & $2 \mathrm{C}$ & 1.3873 & - & - \\
\hline $3 \mathrm{C}$ & 1.4093 & 120.1 & - & $3 \mathrm{C}$ & 1.4003 & 121.4 & - & $3 \mathrm{C}$ & 1.4026 & 120.4 & - \\
\hline $4 \mathrm{C}$ & 1.4080 & 120.4 & 0.5 & $4 \mathrm{C}$ & 1.4008 & 117.6 & 0.6 & $4 \mathrm{C}$ & 1.3991 & 119.3 & 0.9 \\
\hline $5 \mathrm{C}$ & 1.3808 & 120.6 & -0.8 & $5 \mathrm{C}$ & 1.3931 & 121.8 & 0.3 & $5 \mathrm{C}$ & 1.3968 & 120.1 & 0.3 \\
\hline $6 \mathrm{C}$ & 1.4265 & 119.1 & -0.6 & $6 C$ & 1.4006 & 120.4 & -0.8 & $6 C$ & 1.3985 & 120.7 & -1.3 \\
\hline $12 \mathrm{~N}$ & 1.3682 & 122.3 & -178.8 & $11 \mathrm{~N}$ & 1.4136 & 119.0 & -177.6 & $11 \mathrm{~N}$ & 1.4167 & 121.9 & 178.5 \\
\hline $13 \mathrm{C}$ & 1.4208 & 127.8 & 9.0 & $12 \mathrm{C}$ & 1.3855 & 126.7 & -143.5 & $12 \mathrm{C}$ & 1.3841 & 126.1 & 43.5 \\
\hline $14 \mathrm{C}$ & 2.8357 & 140.8 & -175.6 & $13 \mathrm{C}$ & 2.8580 & 139.7 & 159.7 & $13 \mathrm{C}$ & 2.8578 & 139.9 & 158.3 \\
\hline $15 \mathrm{~S}$ & 1.7666 & 110.0 & -140.7 & $14 \mathrm{~S}$ & 1.8047 & 109.8 & -168.5 & $14 \mathrm{~S}$ & 1.8052 & 109.8 & -170.1 \\
\hline $16 \mathrm{~N}$ & 1.2753 & 125.8 & 37.3 & $15 \mathrm{~N}$ & 1.2760 & 129.1 & 8.4 & $15 \mathrm{~N}$ & 1.2764 & 129.0 & 6.5 \\
\hline $17 \mathrm{~N}$ & 1.3549 & 142.8 & 29.1 & $16 \mathrm{~N}$ & 1.3872 & 142.9 & 23.5 & $16 \mathrm{~N}$ & 1.3876 & 142.9 & 23.2 \\
\hline $18 \mathrm{~N}$ & 1.2548 & 90.0 & -140.8 & $17 \mathrm{~N}$ & 1.2600 & 92.7 & -145.7 & $17 \mathrm{~N}$ & 1.2600 & 92.7 & -146.1 \\
\hline \multicolumn{4}{|c|}{ Substituents } & \multicolumn{4}{|c|}{ Methyl group } & \multicolumn{4}{|c|}{ Methoxy group } \\
\hline- & - & - & - & $23 \mathrm{C}$ & 1.5101 & 121.3 & 179.3 & 230 & 1.3645 & 115.8 & -179.1 \\
\hline- & - & - & - & - & - & - & - & $24 \mathrm{C}$ & 1.4195 & 118.2 & -179.8 \\
\hline
\end{tabular}


Table 3. Structural parameters for the thioamidine series.

\begin{tabular}{|c|c|c|c|c|c|c|c|c|c|c|c|}
\hline \multicolumn{4}{|c|}{ TAD a } & \multicolumn{4}{|c|}{ TAD b } & \multicolumn{4}{|c|}{ TAD c } \\
\hline Symbol & $\begin{array}{c}\text { Bond } \\
\text { Length }\end{array}$ & $\begin{array}{l}\text { Bond } \\
\text { Angle }\end{array}$ & $\begin{array}{c}\text { Dihedral } \\
\text { Angle }\end{array}$ & Symbol & $\begin{array}{l}\text { Bond } \\
\text { Length }\end{array}$ & $\begin{array}{l}\text { Bond } \\
\text { Angle }\end{array}$ & $\begin{array}{c}\text { Dihedral } \\
\text { Angle }\end{array}$ & Symbol & $\begin{array}{c}\text { Bond } \\
\text { Length }\end{array}$ & $\begin{array}{l}\text { Bond } \\
\text { Angle }\end{array}$ & $\begin{array}{c}\text { Dihedral } \\
\text { Angle }\end{array}$ \\
\hline $2 \mathrm{C}$ & 1.4079 & - & - & $2 \mathrm{C}$ & 1.4043 & - & - & $2 \mathrm{C}$ & 1.3998 & - & - \\
\hline $3 \mathrm{C}$ & 1.4075 & 118.20 & - & $3 C$ & 1.4034 & 118.65 & - & $3 C$ & 1.4078 & 118.44 & - \\
\hline $4 \mathrm{C}$ & 1.3938 & 120.59 & -0.04 & $4 \mathrm{C}$ & 1.3959 & 120.26 & -1.77 & $4 \mathrm{C}$ & 1.3892 & 120.65 & -1.66 \\
\hline $5 \mathrm{C}$ & 1.3961 & 120.52 & 0.02 & $5 \mathrm{C}$ & 1.3980 & 121.48 & 0.21 & $5 \mathrm{C}$ & 1.4012 & 120.44 & 0.18 \\
\hline $6 \mathrm{C}$ & 1.3901 & 121.10 & 0.05 & $6 \mathrm{C}$ & 1.3897 & 120.39 & 2.22 & $6 \mathrm{C}$ & 1.3944 & 121.19 & 2.18 \\
\hline $11 \mathrm{~N}$ & 1.3994 & 115.74 & -179.97 & $11 \mathrm{~N}$ & 1.4063 & 118.40 & 178.74 & $11 \mathrm{~N}$ & 1.4087 & 118.57 & 178.52 \\
\hline $12 \mathrm{C}$ & 3.6210 & 155.80 & 179.07 & $12 \mathrm{C}$ & 3.5924 & 143.80 & 129.42 & $12 \mathrm{C}$ & 3.5878 & 143.87 & 126.76 \\
\hline $14 \mathrm{C}$ & 1.2638 & 132.83 & 179.33 & $14 \mathrm{C}$ & 1.2698 & 122.82 & 130.39 & $14 \mathrm{C}$ & 1.2691 & 122.81 & 130.21 \\
\hline $15 \mathrm{~N}$ & 1.3858 & 13.93 & 179.44 & $15 \mathrm{~N}$ & 1.3800 & 16.93 & 170.28 & $15 \mathrm{~N}$ & 1.3798 & 17.47 & 162.61 \\
\hline $16 \mathrm{~N}$ & 1.2638 & 134.34 & 179.42 & $16 \mathrm{~N}$ & 1.2702 & 137.91 & 171.94 & $16 \mathrm{~N}$ & 1.2699 & 137.39 & -172.38 \\
\hline $17 \mathrm{~S}$ & 1.8955 & 127.56 & 0.25 & $17 \mathrm{~S}$ & 1.8131 & 126.94 & -1.93 & $17 \mathrm{~S}$ & 1.8137 & 126.78 & -3.77 \\
\hline $18 \mathrm{~S}$ & 1.8959 & 98.10 & -0.76 & $18 \mathrm{~S}$ & 1.8123 & 95.19 & -8.87 & $18 \mathrm{~S}$ & 1.8115 & 95.66 & -0.12 \\
\hline $19 \mathrm{C}$ & 3.6716 & 155.18 & -179.00 & $19 \mathrm{C}$ & 3.6930 & 134.25 & -161.16 & $24 \mathrm{C}$ & 3.6961 & 133.12 & 152.45 \\
\hline $20 \mathrm{C}$ & 1.3981 & 103.10 & -1.99 & $20 \mathrm{C}$ & 1.3980 & 102.09 & -66.70 & $25 \mathrm{C}$ & 1.3976 & 102.00 & 69.93 \\
\hline $21 \mathrm{C}$ & 1.3961 & 119.46 & -0.03 & $21 \mathrm{C}$ & 1.3944 & 119.48 & -0.15 & $26 \mathrm{C}$ & 1.3948 & 119.49 & -0.10 \\
\hline $22 \mathrm{C}$ & 1.3938 & 120.52 & 0.02 & $22 \mathrm{C}$ & 1.3958 & 120.47 & 0.65 & $27 \mathrm{C}$ & 1.3954 & 120.48 & -0.58 \\
\hline $23 \mathrm{C}$ & 1.3994 & 132.82 & 179.96 & $23 \mathrm{C}$ & 1.4053 & 120.15 & 0.29 & $28 \mathrm{C}$ & 1.4052 & 120.12 & -0.22 \\
\hline $24 \mathrm{C}$ & 1.3902 & 17.03 & 178.09 & $24 \mathrm{C}$ & 1.3918 & 18.40 & 113.01 & $29 \mathrm{C}$ & 1.3922 & 18.46 & -109.28 \\
\hline
\end{tabular}




\section{Substituents}

$-$
Methyl group

$30 \mathrm{C}$

$1.5101 \quad 121.41$

$-$

$-$

$-$

$-\quad-$

Table 4. Structural parameters for the thiourea series.

\begin{tabular}{|c|c|c|c|c|c|c|c|c|c|c|c|}
\hline \multicolumn{4}{|c|}{ THIOa } & \multicolumn{4}{|c|}{ THIOb } & \multicolumn{4}{|c|}{ THIOc } \\
\hline Symbol & $\begin{array}{c}\text { Bond } \\
\text { Length }\end{array}$ & $\begin{array}{l}\text { Bond } \\
\text { Angle }\end{array}$ & $\begin{array}{c}\text { Dihedral } \\
\text { Angle }\end{array}$ & Symbol & $\begin{array}{c}\text { Bond } \\
\text { Length }\end{array}$ & $\begin{array}{l}\text { Bond } \\
\text { Angle }\end{array}$ & $\begin{array}{c}\text { Dihedral } \\
\text { Angle }\end{array}$ & Symbol & $\begin{array}{c}\text { Bond } \\
\text { Length }\end{array}$ & $\begin{array}{l}\text { Bond } \\
\text { Angle }\end{array}$ & $\begin{array}{c}\text { Dihedral } \\
\text { Angle }\end{array}$ \\
\hline $2 \mathrm{C}$ & 1.4174 & - & - & $2 \mathrm{C}$ & 1.4022 & - & - & $2 \mathrm{C}$ & 1.3969 & - & - \\
\hline $3 \mathrm{C}$ & 1.4414 & 117.7 & - & $3 \mathrm{C}$ & 1.4023 & 118.9 & - & $3 C$ & 1.4067 & 118.7 & - \\
\hline $4 \mathrm{C}$ & 1.3949 & 119.5 & -2.4 & $4 \mathrm{C}$ & 1.3947 & 119.9 & 1.6 & $4 \mathrm{C}$ & 1.3868 & 120.5 & 1.3 \\
\hline $5 \mathrm{C}$ & 1.3960 & 122.4 & 0.8 & $5 \mathrm{C}$ & 1.3995 & 121.7 & -1.3 & $5 \mathrm{C}$ & 1.4037 & 120.6 & -1.5 \\
\hline $6 \mathrm{C}$ & 1.3831 & 121.7 & 1.5 & $6 \mathrm{C}$ & 1.3911 & 120.4 & -0.5 & $6 \mathrm{C}$ & 1.3952 & 121.0 & 0.0 \\
\hline $12 \mathrm{~N}$ & 1.3909 & 119.7 & -177.7 & $11 \mathrm{~N}$ & 1.4170 & 118.6 & -177.5 & $11 \mathrm{~N}$ & 1.4304 & 120.1 & -178.2 \\
\hline $13 \mathrm{~N}$ & 2.3680 & 100.5 & 140.2 & $12 \mathrm{~N}$ & 2.3265 & 98.6 & -139.3 & $12 \mathrm{~N}$ & 2.3231 & 95.5 & -124.8 \\
\hline $14 \mathrm{~S}$ & 2.7108 & 157.5 & -172.6 & $13 \mathrm{~S}$ & 2.6554 & 163.0 & -144.2 & $13 \mathrm{~S}$ & 2.7001 & 160.0 & -132.8 \\
\hline $15 \mathrm{C}$ & 1.3759 & 130.1 & 154.5 & $14 \mathrm{C}$ & 1.3598 & 31.6 & -178.7 & $14 \mathrm{C}$ & 1.3508 & 31.5 & -176.6 \\
\hline \multicolumn{4}{|c|}{ Substituents } & \multicolumn{4}{|c|}{ Methyl group } & \multicolumn{4}{|c|}{ Methoxy group } \\
\hline- & - & - & - & $18 \mathrm{C}$ & 1.5098 & 121.3 & 179.2 & 180 & 1.3817 & 115.8 & -179.4 \\
\hline- & - & - & - & - & - & - & - & $19 \mathrm{C}$ & 1.4612 & 118.2 & 179.3 \\
\hline
\end{tabular}


DTA a

Series 1:

Dithiazolidine

derivatives

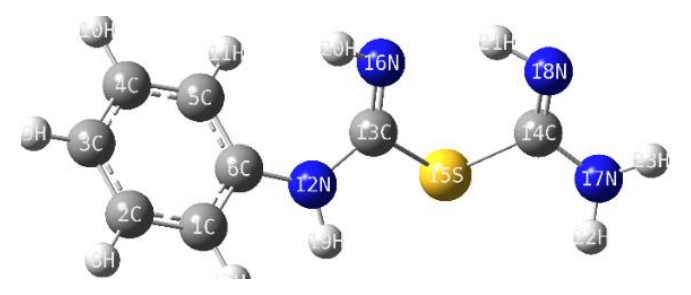

TAD a

Series 2:

Thioamidine

derivative
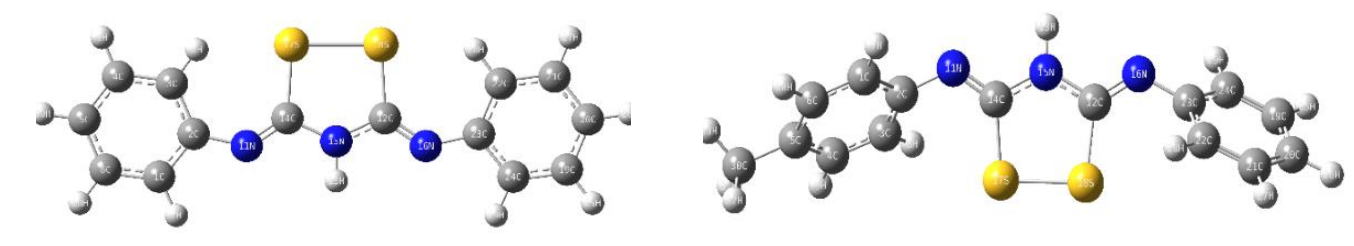

TAD b

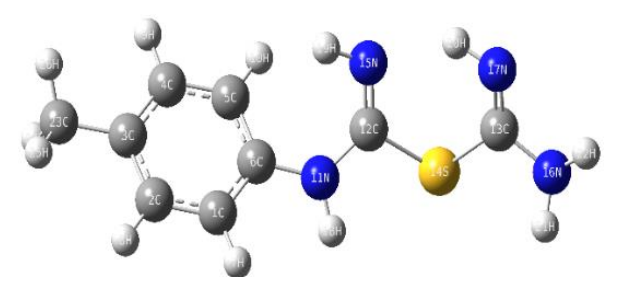

DTA b

DTA c

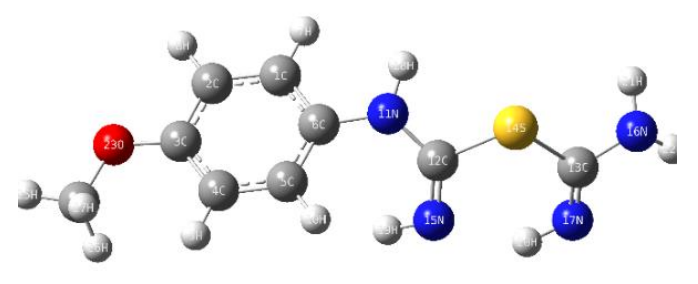

TAD c

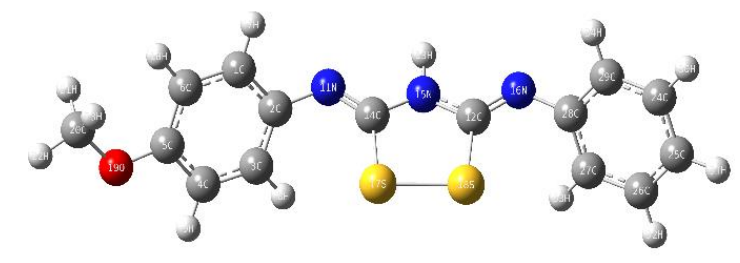

THIO a

Series 3:

Thiourea derivatives
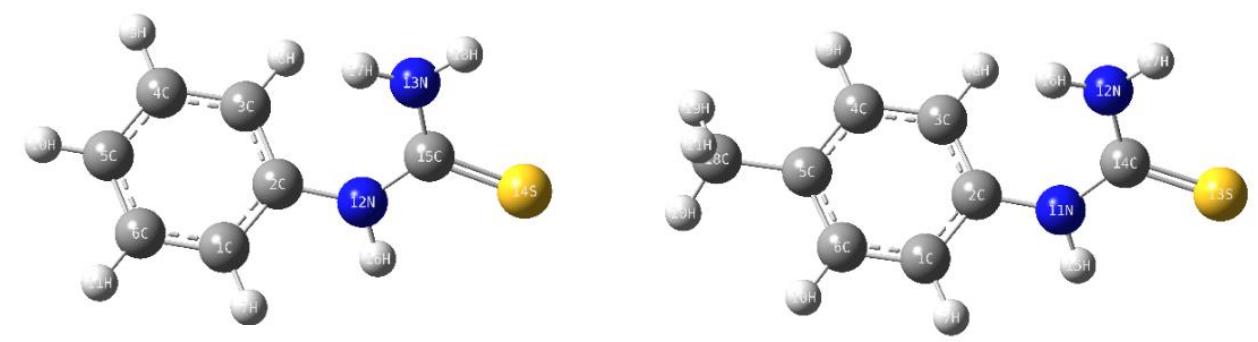

THIO c

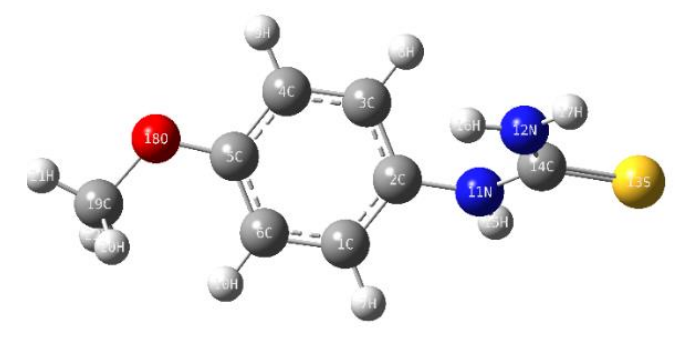

Figure 1. Optimized lowest energy conformation for the inhibitor system used in the current investigation. 


\subsection{Molecular properties of the heterocyclic systems}

Quantum chemical parameters related to the molecular electronic structures of the nonprotonated form of studied compounds (Figures 2-4 and Tables 5-8) showing an excellent relationship with the inhibition efficiency is discussed as follows.

\section{HOMO Distribution}

DTA a

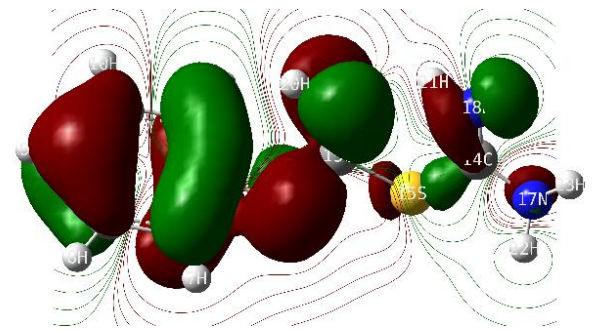

DTA b

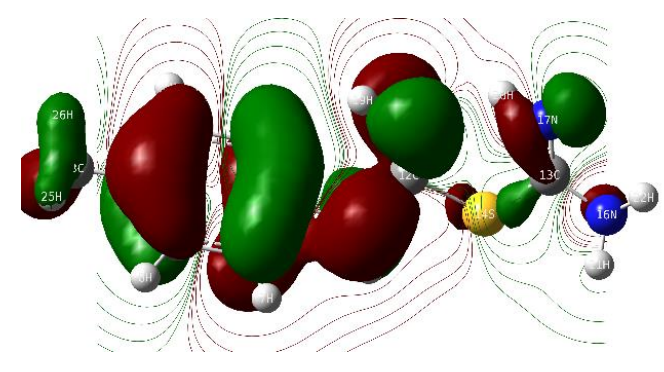

DTA c

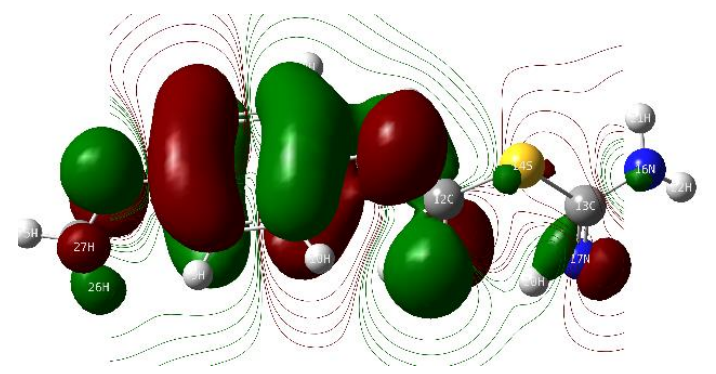

\section{LUMO Distribution}
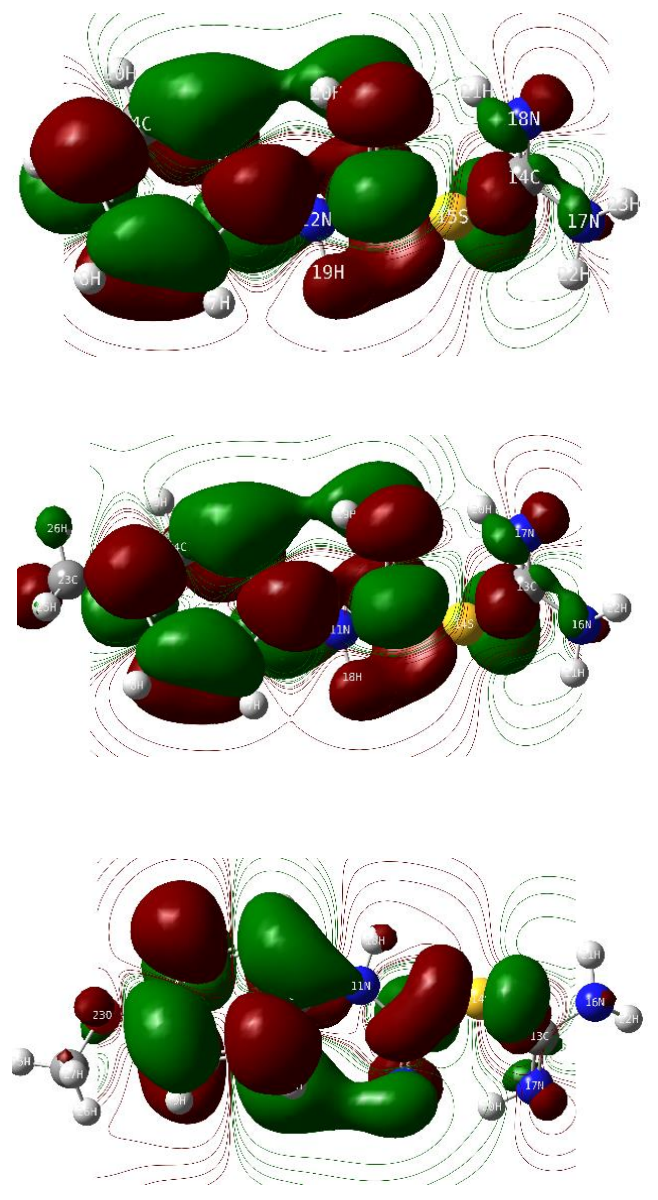

Figure 2. Optimized geometry of dithiazolidine derivatives DTA a-DTA $\mathrm{c}$. 
HOMO Distribution

TAD a

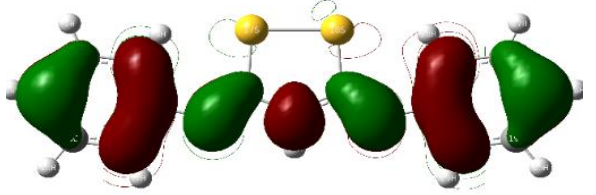

TAD b

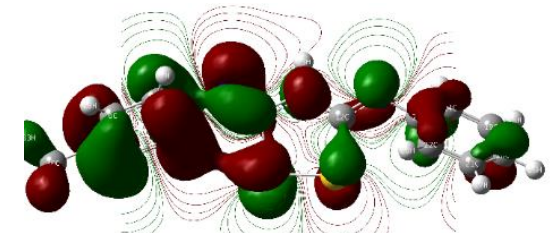

TAD c

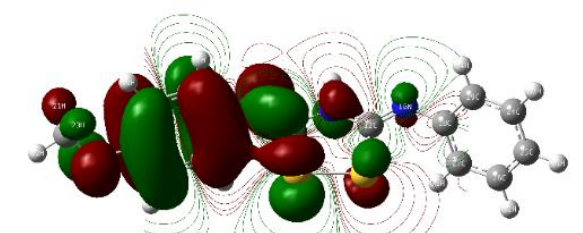

\section{LUMO Distribution}
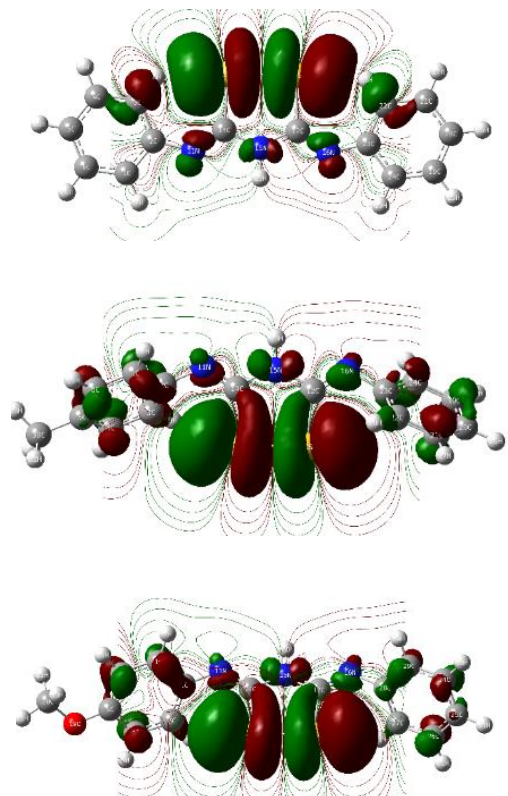

Figure 3. Optimized geometry of thioamidine derivatives TAD a - TAD c.

HOMO Distribution

THIO a

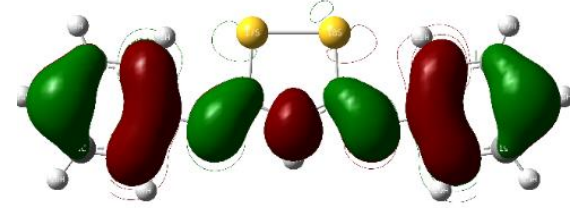

THIO b

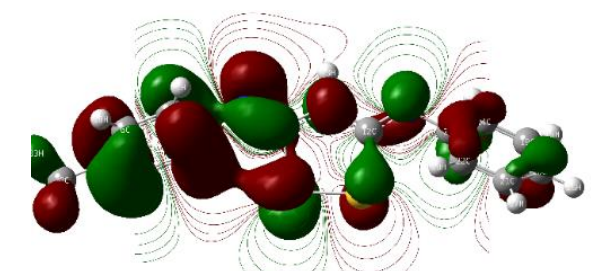

THIO c

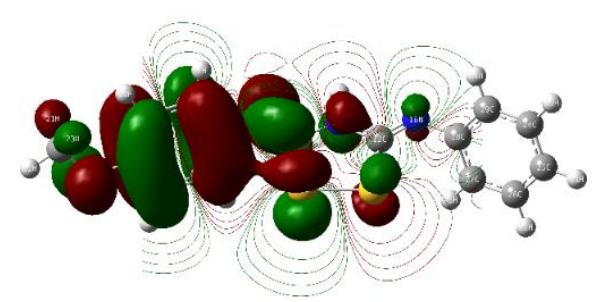

\section{LUMO Distribution}
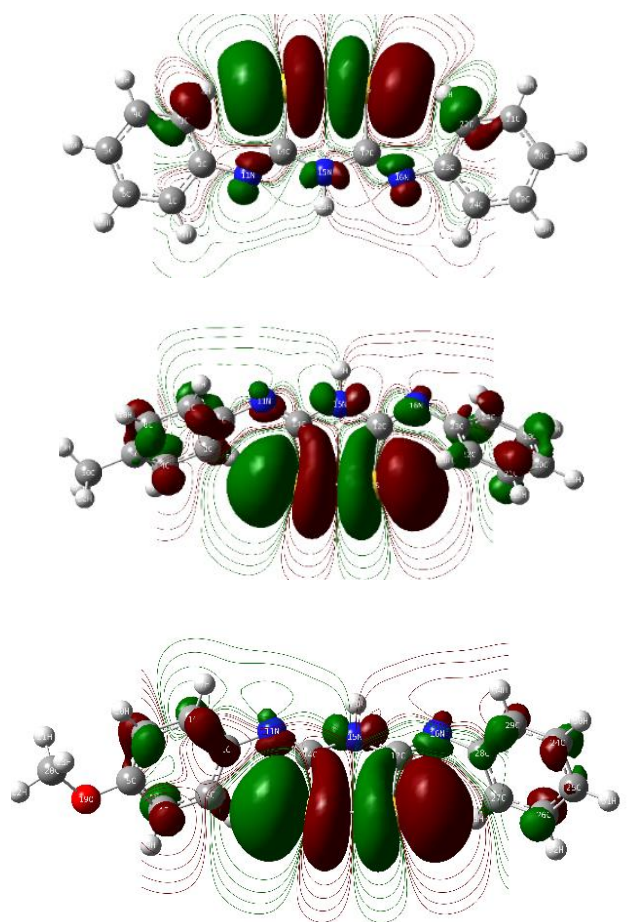

Figure 4. Optimized geometry of thiourea derivatives THIO a-THIO c. 
Table 5. Theoretical properties of dithiazolidine derivatives.

\begin{tabular}{cccc}
\hline Properties & DTA a & DTA b & DTA c \\
\hline Empirical Formula & $\mathrm{C}_{8} \mathrm{H}_{10} \mathrm{~N}_{4} \mathrm{~S}$ & $\mathrm{C}_{9} \mathrm{H}_{12} \mathrm{~N}_{4} \mathrm{~S}$ & $\mathrm{C}_{9} \mathrm{H}_{12} \mathrm{~N}_{4} \mathrm{SO}$ \\
Total Energy $(\mathrm{eV})$ & -928 & -967 & -1042 \\
Dipole Moment (Debye) & 4.43 & 4.77 & 4.95 \\
Ionisation Potential $(\mathrm{eV})$ & 8.74 & 8.83 & 8.30 \\
HOMO energy $(\mathrm{eV})$ & -8.748 & -8.831 & -8.307 \\
LUMO energy $(\mathrm{eV})$ & 0.105 & -0.239 & -0.996 \\
Energy Gap $(\mathrm{eV})$ & 8.85 & 8.59 & 7.31 \\
Heat of formation kcal/mol & 67.54 & 57.70 & 64.36 \\
Zero Point energy kcal/mol & 126.20 & 120.90 & 126.21 \\
Global Hardness $(\eta)$ & 120.45 & 116.90 & 99.47 \\
Absolute Softness $(\sigma)$ & 0.01 & 0.01 & 0.01 \\
Electronegativity $(\chi)$ & 117.60 & 123.41 & 126.58 \\
Electrophilicity & 57.40 & 65.14 & 80.53 \\
Fraction of Electron Transferred $(\Delta N)$ & 0.46 & 0.50 & 0.53 \\
Fraction of Energy Transferred $(\Delta E)$ & -25.39 & -28.98 & -35.94 \\
TNC & 2.77 & 2.80 & 3.32 \\
\hline
\end{tabular}

Table 6. Theoretical properties of thioamidine derivatives.

\begin{tabular}{cccc}
\hline Properties & TAD a & TAD b & TAD c \\
\hline Empirical Formula & $\mathrm{C}_{14} \mathrm{H}_{11} \mathrm{~N}_{3} \mathrm{~S}_{2}$ & $\mathrm{C}_{15} \mathrm{H}_{13} \mathrm{~N}_{3} \mathrm{~S}_{2}$ & $\mathrm{C}_{15} \mathrm{H}_{13} \mathrm{~N}_{2} \mathrm{~S}_{2} \mathrm{O}$ \\
Total Energy $(\mathrm{eV})$ & -1492 & -1540 & -1615 \\
Dipole Moment (Debye) & 0.74 & 0.85 & 1.52 \\
Ionisation Potential $(\mathrm{eV})$ & 8.89 & 8.33 & 7.73 \\
HOMO energy $(\mathrm{eV})$ & -8.897 & -8.330 & -7.736 \\
LUMO energy $(\mathrm{eV})$ & 0.150 & 0.227 & 0.123 \\
Energy Gap $(\mathrm{eV})$ & 9.047 & 8.557 & 7.859 \\
Heat of formation kcal/mol & 25.75 & 17.19 & -7.75 \\
Zero Point energy kcal/mol & 43.88 & 42.78 & 60.79 \\
Global Hardness $(\eta)$ & 123.09 & 116.43 & 106.93 \\
Absolute Softness $(\sigma)$ & 0.01 & 0.01 & 0.01 \\
Electronegativity $(\chi)$ & 119.01 & 110.25 & 103.58 \\
\hline
\end{tabular}




\begin{tabular}{cccc}
\hline Properties & TAD a & TAD b & TAD c \\
\hline Electrophilicity & 57.53 & 52.20 & 50.17 \\
Fraction of Electron Transferred $(\Delta N)$ & 0.44 & 0.45 & 0.45 \\
Fraction of Energy Transferred $(\Delta E)$ & -25.48 & -22.89 & -21.81 \\
TNC & 3.38 & 3.79 & 4.13 \\
\hline
\end{tabular}

Table 7. Theoretical properties of thiourea derivatives.

\begin{tabular}{cccc}
\hline Properties & THIO a & THIO b & THIO c \\
\hline Empirical Formula & $\mathrm{C}_{7} \mathrm{H}_{8} \mathrm{~N}_{2} \mathrm{~S}$ & $\mathrm{C}_{8} \mathrm{H}_{10} \mathrm{~N}_{2} \mathrm{~S}$ & $\mathrm{C}_{8} \mathrm{H}_{10} \mathrm{~N}_{2} \mathrm{SO}$ \\
Total Energy $(\mathrm{eV})$ & -779 & -818 & -889 \\
Dipole Moment (Debye) & 5.45 & 6.01 & 7.55 \\
Ionization Potential $(\mathrm{eV})$ & 9.37 & 8.82 & 8.20 \\
HOMO energy $(\mathrm{eV})$ & -9.374 & -8.825 & -8.203 \\
LUMO energy $(\mathrm{eV})$ & -0.696 & -0.684 & -0.494 \\
Energy Gap $(\mathrm{eV})$ & 8.678 & 8.141 & 7.709 \\
Heat of formation kcal/mol & 50.69 & 40.89 & 47.75 \\
Zero Point energy kcal/mol & 80.05 & 74.77 & 81.97 \\
Global Hardness $(\eta)$ & 118.07 & 110.77 & 104.89 \\
Absolute Softness $(\sigma)$ & 0.01 & 0.01 & 0.01 \\
Electronegativity $(\chi)$ & 137.01 & 129.38 & 118.33 \\
Electrophilicity & 79.49 & 75.56 & 66.75 \\
Fraction of Electron Transferred $(\Delta N)$ & 0.55 & 0.55 & 0.60 \\
Fraction of Energy Transferred $(\Delta E)$ & -35.79 & -33.80 & -29.54 \\
TNC & 2.32 & 3.27 & 3.55 \\
\hline
\end{tabular}


Table 8. Mulliken charge density and Fukui indices for the atoms present in diathiazolidine series.

\begin{tabular}{|c|c|c|c|c|c|c|c|c|c|c|c|c|c|c|c|c|c|}
\hline \multirow{2}{*}{ Atoms } & \multicolumn{5}{|c|}{ DTA a } & \multirow{2}{*}{ Atoms } & \multicolumn{5}{|c|}{ DTA b } & \multirow{2}{*}{ Atoms } & \multicolumn{5}{|c|}{ DTA c } \\
\hline & $q_{N}$ & $f^{+}$ & $f^{-}$ & $S^{+}$ & $S^{-}$ & & qN & $f^{+}$ & $f^{-}$ & $S^{+}$ & $S^{-}$ & & $\mathbf{q N}$ & $f^{+}$ & $\boldsymbol{f}^{-}$ & $S^{+}$ & $S^{-}$ \\
\hline $1 \mathrm{C}$ & -0.12 & 0.03 & 0.01 & 0.01 & 0.00 & $1 \mathrm{C}$ & -0.11 & 0.02 & 0.01 & 0.01 & 0 & $1 \mathrm{C}$ & -0.11 & 0.1 & 0.01 & 0.05 & 0 \\
\hline $2 \mathrm{C}$ & -0.09 & 0.01 & 0.01 & 0.00 & 0.00 & $2 \mathrm{C}$ & -0.13 & 0.03 & 0.02 & 0.01 & 0.01 & $2 \mathrm{C}$ & -0.12 & 0.03 & 0.01 & 0.01 & 0 \\
\hline $3 \mathrm{C}$ & -0.08 & 0.04 & 0.05 & 0.02 & 0.02 & $3 \mathrm{C}$ & 0.13 & 0.01 & 0.03 & 0 & 0.01 & $3 \mathrm{C}$ & 0.36 & 0.03 & 0.02 & 0.01 & 0.01 \\
\hline $4 \mathrm{C}$ & -0.08 & 0.00 & 0.02 & 0.00 & 0.01 & $4 \mathrm{C}$ & -0.13 & 0.02 & 0.01 & 0.01 & 0 & $4 \mathrm{C}$ & -0.14 & 0.02 & 0.01 & 0.01 & 0 \\
\hline $5 \mathrm{C}$ & -0.09 & 0.00 & 0.05 & 0.00 & 0.02 & $5 \mathrm{C}$ & -0.11 & 0.02 & 0.04 & 0.01 & 0.02 & $5 \mathrm{C}$ & -0.12 & 0.02 & 0.02 & 0.01 & 0.01 \\
\hline $6 \mathrm{C}$ & -0.18 & 0.51 & -0.45 & 0.25 & -0.22 & $6 C$ & 0.28 & 0.06 & 0.01 & 0.03 & 0 & $6 \mathrm{C}$ & 0.27 & 0.07 & -0.03 & 0.03 & -0.01 \\
\hline $12 \mathrm{~N}$ & 0.29 & -0.83 & 0.86 & -0.41 & 0.42 & $11 \mathrm{~N}$ & -0.6 & 0.05 & -0.02 & 0.02 & -0.01 & $11 \mathrm{~N}$ & -0.6 & 0.04 & 0 & 0.02 & 0 \\
\hline $13 \mathrm{C}$ & -0.60 & 0.89 & -0.42 & 0.44 & -0.21 & $12 \mathrm{C}$ & 0.3 & -0.02 & 0.11 & -0.01 & 0.05 & $12 \mathrm{C}$ & 0.3 & -0.02 & 0 & -0.01 & 0 \\
\hline $14 \mathrm{C}$ & 0.30 & 0.04 & 0.94 & 0.02 & 0.46 & $13 \mathrm{C}$ & 0.28 & 0.04 & 0.01 & 0.02 & 0 & $13 \mathrm{C}$ & 0.28 & 0.03 & 0.02 & 0.01 & 0.01 \\
\hline $15 S$ & 0.28 & -0.10 & 0.33 & -0.05 & 0.16 & $14 S$ & 0.09 & 0.08 & 0.59 & 0.04 & 0.29 & $14 \mathrm{~S}$ & 0.09 & 0.07 & 0.66 & 0.03 & 0.32 \\
\hline $16 \mathrm{~N}$ & 0.09 & -0.58 & -0.18 & -0.28 & -0.09 & $15 \mathrm{~N}$ & -0.57 & 0.08 & 0.07 & 0.04 & 0.03 & $15 \mathrm{~N}$ & -0.57 & 0.07 & -0.01 & 0.03 & 0 \\
\hline $17 \mathrm{~N}$ & -0.56 & -0.01 & 0.04 & 0.00 & 0.02 & $16 \mathrm{~N}$ & -0.59 & 0.01 & 0.01 & 0 & 0 & $16 \mathrm{~N}$ & -0.59 & 0.01 & -0.01 & 0 & 0 \\
\hline $18 \mathrm{~N}$ & -0.59 & 0.10 & 0.01 & 0.05 & 0.00 & $17 \mathrm{~N}$ & -0.54 & 0.04 & 0.06 & 0.02 & 0.03 & $17 \mathrm{~N}$ & -0.54 & 0.04 & 0.08 & 0.02 & 0.04 \\
\hline- & - & - & - & - & - & $23 \mathrm{C}$ & -0.38 & -0.02 & -0.01 & -0.01 & 0 & 230 & -0.52 & -0.02 & 0.01 & -0.01 & 0 \\
\hline- & - & - & - & - & - & - & - & - & - & - & - & $24 \mathrm{C}$ & -0.07 & -0.05 & -0.01 & -0.02 & 0 \\
\hline
\end{tabular}




\section{Molecular orbital energy}

Highest occupied molecular orbital energy $\left(E_{\text {НОмо }}\right)$ and lowest unoccupied molecular orbital energy $\left(E_{\mathrm{LUMO}}\right)$, also called the frontier orbitals, determine the way the molecule interacts with other species. The HOMO is the orbital that could act as an electron donor since it is the outermost (highest energy) orbital containing electrons. The LUMO is the orbital that could act as the electron acceptor, since it is the innermost (lowest energy) orbital that has room to accept electrons $[18,19]$. So an increase in the values of $E_{\mathrm{HOMO}}$ and lower $E_{\mathrm{LUMO}}$ can facilitate adsorption and therefore the inhibition efficiency. The energy of the HOMO is directly related to the ionization potential and the energy of the LUMO is directly related to the electron affinity [20].

The HOMO-LUMO gap, i.e. the difference in energy between the HOMO and LUMO, is an important stability index [21]. A large HOMO-LUMO gap implies high stability for the molecule in chemical reactions. Therefore, a low value of $\Delta E$ is an indication of good inhibition efficiency [22]. The concept of "activation hardness" has been also defined based on the energy gap. Hardness is closely related to polarizability since a decrease of the energy gap usually leads to easier polarization of the molecule [23]. The frontier orbital distribution among the studied compounds is explained as follows.

The more negative atoms are capable of donating their electrons to the vacant $d$ orbitals of the metal atom and are represented in the homo distribution where more positive centers are described by LUMO distribution [2]. As evident from the figures (Figures 2-4), the HOMO centers are exclusively localized over the entire molecule in diathiazolidine series. In thioamidine series HOMO centers are the aromatic rings in conjugation with the electron rich $N$ atom whereas in thiourea series it is centered mainly on the hetero atoms, which are the binding centres to the metal [24]. The LUMO has a strongly $\pi^{*}$ (antibonding) character and in all the dithiazolidine derivatives, LUMO is localized over the entire molecule as in the HOMO distribution, in thioamidine series LUMO centres are around the $S$ atom and in the thiourea series it is centred on the substituted benzene ring, through which the molecule can accept electrons from the Fe atom with its antibonding orbital to form a back-donating bond [25-27]. However, electron acceptance in this orbital is not favourable because of the aromatic requirement [7].

Figures 5-7 summarize the schematic diagram of frontier molecular orbitals for the investigate compounds to their estimated energy gap. As $\Delta E$ decreases, the reactivity of the molecule increases leading to an increase in the inhibition efficiency of the molecule $[26,28]$. The $\Delta E$ value among the series showed that the methoxy derivative has the lowest energy gap together with the highest HOMO energy in all the three series of compounds studied. Hence it is the methoxy derivative that is expected to have a greater resistivity towards corrosion by getting easily adsorbed on the metal surface than the other compounds [1] as it is easy to remove its outermost electron. 


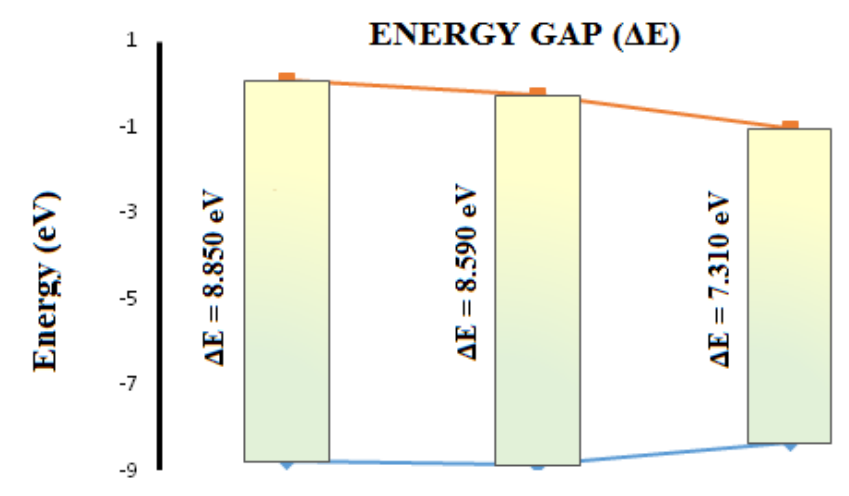

Figure 5. Schematic diagram of frontier molecular orbitals for diathiazolidine series for their estimated energy gap.

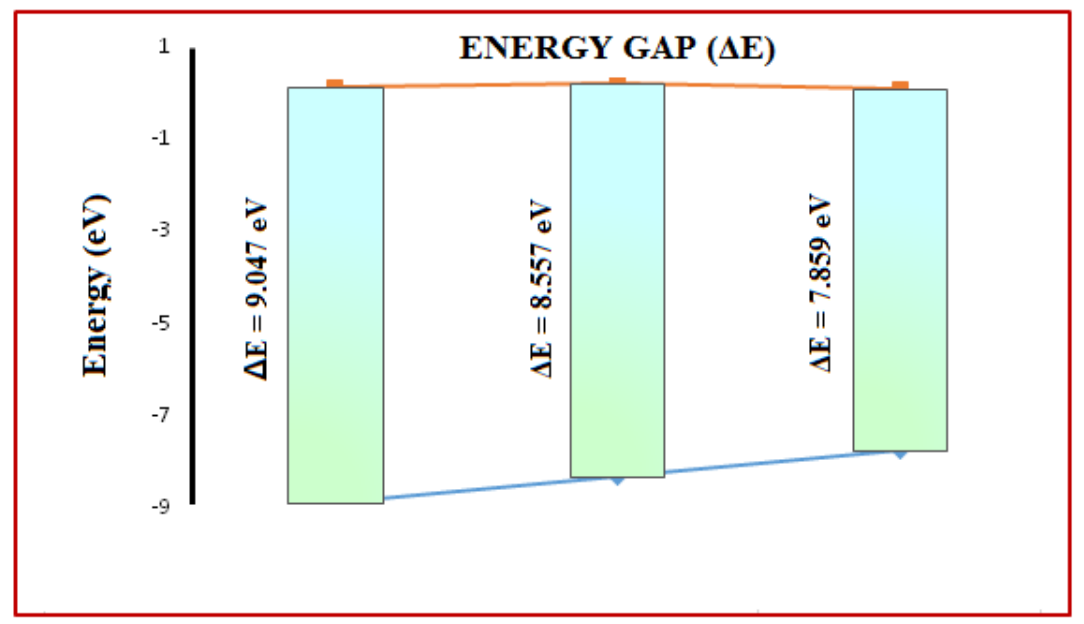

Figure 6. Schematic diagram of frontier molecular orbitals for thioamidine series for their estimated energy gap. 


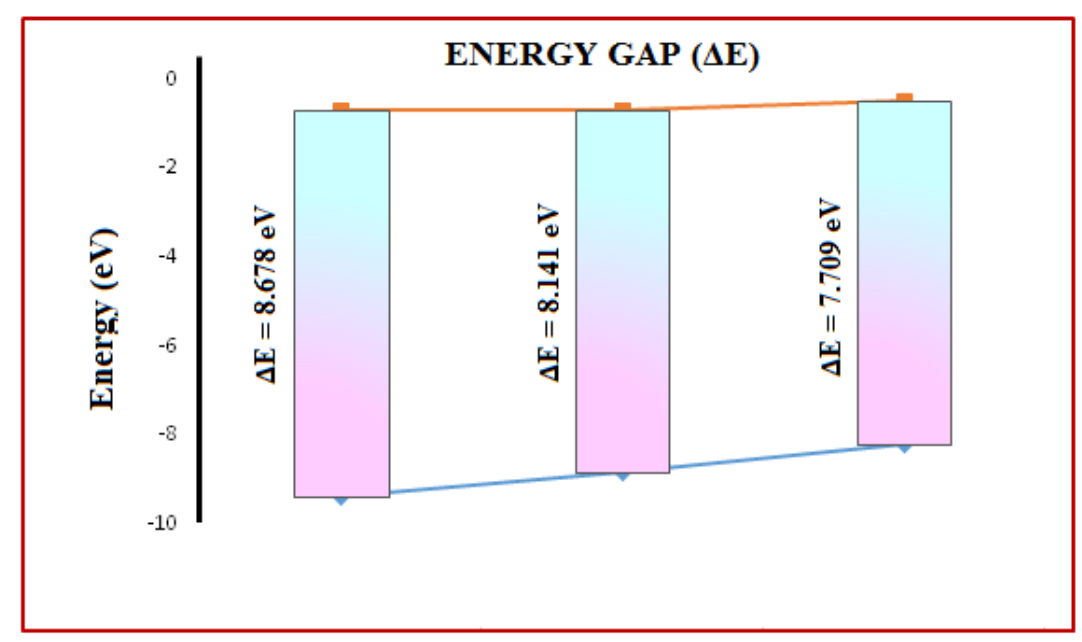

Figure 7. Schematic diagram of frontier molecular orbitals for thiourea series for their estimated energy gap.

\section{Dipole moment}

The dipole moment $(\mu)$ is the measure of polarity in a bond and is related to the distribution of electrons in a molecule. The adsorption of polar compounds possessing high dipole moments on the metal surface should lead to better inhibition efficiency [29]. Among the studied compounds the trend in dipole moment is as follows:

Series 1: compound DTA c (4.95) > compound DTA b (4.77) > compound DTA a (4.43)

Series 2: compound TAD c (1.52) > compound TAD b (0.85) > compound TAD a (0.74) Series 3: compound THIO c (7.55) > compound DTA a (6.01) > compound DTA b (5.45)

Generally, there is no definite trend in the relationship between dipole moment and inhibition efficiency. But generally, a more polar compound is expected to have greater charge separations that result in better adsorption. In this regard, the trend obtained is in consistency with the results obtained from other quantum chemical parameters [30].

\section{Ionization potential and Electron affinity}

The Hartree-Fock theorem establishes a relationship between the energies of HOMO and LUMO and ionization potential and electron affinity. The inhibition efficiencies of the inhibitor increase with increasing ionization energy but decrease with decreasing value of electron affinity as ionization potential is directly related with the $E_{\mathrm{HOMO}}$, while electron affinity is related to the $E_{\mathrm{LUMO}}[31,32]$.

\section{Electronegativity}

Electronegativity $(\chi)$ is a chemical property that describes the ability of a molecule to attract electrons towards itself in a covalent bond. The result deduced indicates that the electron flow will happen from the molecule with the low electronegativity towards that of a higher value. The best inhibitor is attributed to its low electronegativity [33]. When the metal and 
the inhibitor are brought into contact, an electron will flow from lower $\chi$ (inhibitor) to higher $\chi$ (metal), until the chemical potentials become equal.

\section{Fraction of Electrons Transferred}

As the first approximation, the fraction of electrons transferred $(\Delta N)$ from the inhibitor molecule to the metallic atom can be calculated. In order to calculate $\Delta N$, the electronegativity of bulk iron was used as $\chi_{\mathrm{Fe}}=7 \mathrm{eV}$ and global hardness as $\eta_{\mathrm{Fe}}=0$, by assuming that for a metal, bulk ionization potential is equal to the electron affinity, because they are softer than the neutral metallic atoms. The metal surface act as Lewis acid according to HSAB theory. According to Lukovits, if $\Delta N<3.6$, the inhibition efficiency increased with increasing electron donating ability at the metal surface. The greater $E_{\text {Номо value shows the }}$ electron donating ability of a molecule. The fraction of electron transferred by the studied compounds is listed below.

Series 1: compound DTAc $(0.53)>$ compound DTAb $(0.50)>$ compound DTAa $(0.46)$

Series 2 : compound TADc $(0.45)=$ compound TADb $(0.45)>$ compound TADa $(0.44)$

Series 3: compound THIOc $(0.60)>$ compound DTAb $(0.50)=$ compound DTAd $(0.50)$

Thus the fraction of electron transferred from the inhibitor to the metal atom also follows the same trend as that followed by the other parameters. The fraction of electron transferred is high for the indoloimidazoline derivatives which accounts for its highest efficiency among the three series of compounds studied [34].

\section{Total Negative Charge (TNC)}

The total negative charge (TNC) on the molecule accounts for the accumulation of net charge in the molecule. More the negative charge, greater is the electron density in the molecule. Greater will be the electron transferred to the metal surface to get adsorbed on its surface, hence greater is its efficiency [35]. The TNC on each of the compound tabulated in Table 1 follows the order:

\section{Series $1>$ Series $3>$ Series 2}

Thus the dithiazolidine derivatives carry a greater negative charge which accounts for its greater possibility to share electrons to the metal surface.

\subsection{Local selectivity parameters}

The local electron densities or charges are important in many chemical reactions and for physico-chemical properties of compounds. Thus, charge-based parameters are widely employed as chemical reactivity indices or as measures of weak intermolecular interactions. Mulliken population analysis [14] is mostly used for the calculation of the charge distribution in a molecule. Furthermore, atomic charges are used for the description of the molecular polarity of molecules. 


\section{Mulliken Charge Density}

The charge on the atoms also gives information on the electron distribution in the molecule and therefore the reactivity of a molecule. It also informs of the selectivity of the molecule i.e., the specific centers on the molecule for which a certain type of reaction is likely to occur. Centers with the highest negative charge in the molecule are often susceptible to an electrophilic attack [28, 29]. Figure 8 reports the Mulliken atomic charges for the nonhydrogen atoms of the studied molecules.

The Mulliken charge distribution was calculated on the optimized geometry among the non-hydrogen atoms of the three series of compounds, using the B3LYP/6-31G (d, p) method. The results show that $N$ atoms of the heterocyclic ring carry the highest negative charge. These atoms are therefore likely to take part in an electrophilic attack in which case they will readily donate electrons to the electrophilic species. When the electrophilic species is the metal surface, the donated electrons are accepted in the partially filled or vacant $\mathrm{d}$ orbitals of the metal, which allows the molecules to be adsorbed on the metal surface. These results are in agreement with the electron density potential surface, showing that $N$ atoms are susceptible to electrophilic attack [30-32]. All C atoms directly attached to $N$ atoms are electron deficient (i.e., they have positive charge) and therefore could be subject to nucleophilic attack. The benzene ring has a delocalization of slightly negative charge on its atoms; these results suggest that the $\mathrm{N}$ atoms on the heterocyclic ring are possible sites that might interact with the metal surface resulting in a formation of a protective layer on the metal surface [33-36].

In the case of substituents $\left(-\mathrm{OCH}_{3} ;-\mathrm{CH}_{3}\right)$, the $\mathrm{O}$ atom carries a greater negative charge ( $\mathrm{O}$ is more electronegative than $\mathrm{N}$ and therefore has a greater tendency to attract electrons towards itself in the case of methoxy substituent. The $\mathrm{C}$ atoms of the substituents also carry negative charge. Thus the substituent facilitates the donation of an electron by the heterocyclic ring by their electron donating ability [37]. The number of active negatively charged atoms in each compound of the series follows the order:

$$
\text { Methoxy derivative }>\text { Methyl derivative > Parent compound, }
$$

which is the trend in the increase in the electron donating ability among the three derivatives.

\section{Fukui indices}

The local selectivity of an inhibitor was analyzed using condensed Fukui and condensed softness functions. The condensed Fukui function and condensed softness are indices that allow for the distinction of each part of a molecule on the basis of its chemical behavior due to different substituent functional groups $[4,38]$. 
Series 1:

Dithiazolidine derivatives

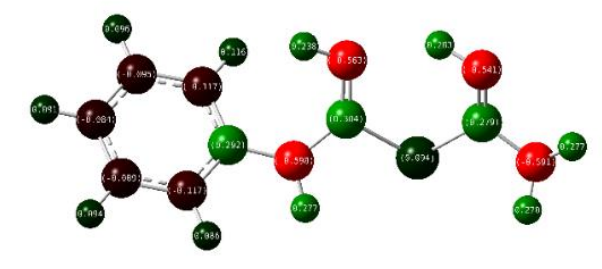

$$
\text { TAD a }
$$

Series 2:

Thioamidine derivative

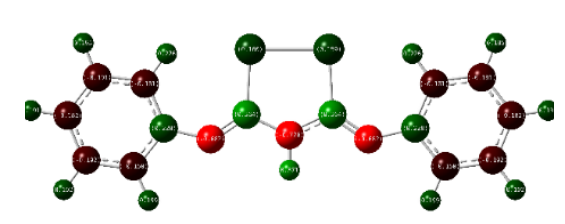

THIO a

Series 3:

Thiourea derivatives
DTA b

DTA c
$0_{0}^{2} 0_{0}^{0} 0_{0}^{0}$

TAD c

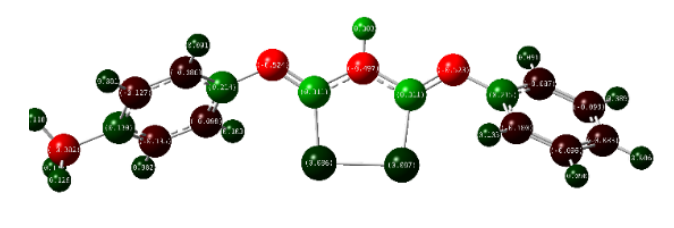

THIO b

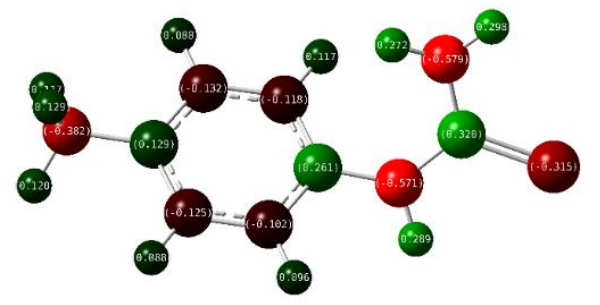

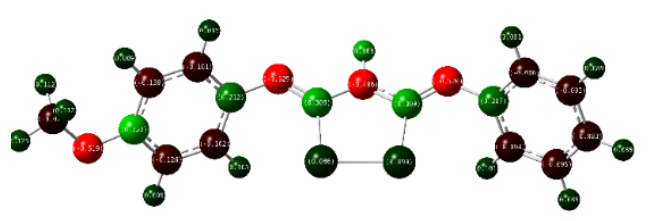

THIO c

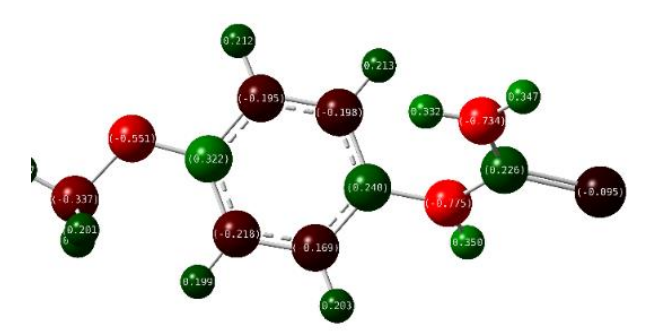

Figure 8. the Mulliken atomic charges for the non-hydrogen atoms of the studied molecules. 
The Fukui function is motivated by the fact that if an electron $\delta$ is transferred to an $N$ electron molecule, it will tend to distribute so as to minimize the energy of the resulting $N$ $+\delta$ electron system. The resulting change in electron density is the nucleophilic $\left(f^{+}\right)$and electrophilic $\left(f^{-}\right)$indices [3]. Fukui functions are calculated as described elsewhere and calculated values of $f^{+}$and $f^{-}$(calculated from Mulliken charges) for the carbon and other electronegative elements are presented in Table 8-10 for the three series of compounds. The molecular sites with large values of $f^{+}$are the sites where the molecular will accept electrons when attacked by a nucleophilic reagent. On the other hand, the molecular sites with large values $f$ are the preferred sites through which the molecule will donate electrons when attacked by an electrophilic reagent. The most susceptible sites for nucleophilic attack are those molecular sites with large values $f^{+}[7,39-41]$.

From Table 8 for the diathiazolidine derivatives, it is clear that the most reactive site for the electrophilic attack was on the atoms in the molecule where there is the highest negative Mulliken charge. The electrophilic reactive sites in compound DTA a are on the three $\mathrm{N}$ heterocyclic ring atoms and the carbon atoms of the aromatic unit. Those of compound DTAb and DTAc are not only on the nitrogen atom but on the substituent atoms also [42-44]. A similar trend was also noted in the other two series. The results obtained from fukui functions support the information obtained from the distributions of $\mathrm{HOMO}$ and LUMO. The HOMO and LUMO distributions on each investigated inhibitor are identical with the atoms that exhibit the greatest values of $f^{-}$and $f^{+}$, respectively, indicating that these reactive sites would be the adsorption centers during the process of corrosion inhibition. In addition, the highest inhibition property of compound three series of heterocyclic compounds should be attributed to the increasing number of centers of adsorption on the inhibitor molecules and the highest electron density confirmed by the highest value of the TNC $[37,41]$.

The local softness is defined as the product of the Fukui function and the global softness (б) and high value of $S^{+}$indicates high nucleophilicity and a high value of $S^{-}$denoted high electrophilicity. The results of Table $8-10$, show that the trend in the $S^{+}$and $S^{-}$is similar to the trend in the $f^{+}$and $f^{-}$values for all the compounds [45-48].

\section{Substitution effect}

Table 11 presents the calculated values of inhibition efficiency $\%$ for the three series of compounds calculated theoretically using the following formula

$$
\begin{gathered}
I_{\text {add }} \%=\frac{I_{\mathrm{IH}}-I_{x-\mathrm{IH}}}{I_{\mathrm{IH}}} \cdot 100 \% \\
I E_{\text {add }} \%=I_{\text {add }} \% \cdot I E_{\mathrm{IH}} \% \\
I E_{\text {Theor }} \%=I E_{\mathrm{IH}} \%+\%
\end{gathered}
$$


Where $I_{\text {add }} \%$ is the percentage ionization potential of the additive for the model $(x-\mathrm{IH}), I E_{\text {add }} \%$ is the calculated inhibition efficiency $\%$ of the substituent and $I E_{\text {Theor }} \%$ is the theoretically calculated percentage inhibition efficiency for that inhibitor. $I_{I H}$ and $I_{x-\mathrm{IH}}$ are the ionization potential of the parent compound and its corresponding $\mathrm{x}$-substituted compound. The results obtained from the table clearly demonstrate that the presence of electron donating groups in addition lead to an increase in the inhibition efficiency; the most effective inhibitor was with methoxy substituents, which displayed an increase in inhibition efficiency from that of the corresponding parent compound by around 3-7\%. The inhibition efficiency of methyl substituents increases the efficiency by nearly 1-3\% from that of the corresponding parent compound [39, 40].

\section{Conclusion}

Based on the results obtained from the studies, the following conclusions were drawn.

1. Theoretical studies were found to a useful tool in predicting the property of an organic compound.

2. The structure of the compound was analyzed from their bond length, bond angle, and dihedral angle. The non-planarity in the molecule was proposed from its dihedral angle.

3. The various molecular properties prove the ability of the molecule to inhibit corrosion by getting adsorbed on the metal surface.

4. The local adsorption sites in the molecule were assessed from its charge density distribution and Fukui indices.

5. The various parameters analyzed were found to fit well with each other which proves the inhibitive nature of the studied systems against metal corrosion.

\section{Acknowledgments}

The authors thank UGC, New Delhi for the financial support. 
Table 9. Mulliken charge density and Fukui indices for the atoms present in thioamidine series.

\begin{tabular}{|c|c|c|c|c|c|c|c|c|c|c|c|c|c|c|c|c|c|}
\hline \multirow{2}{*}{ Atoms } & \multicolumn{5}{|c|}{ THIO a } & \multirow{2}{*}{ Atoms } & \multicolumn{5}{|c|}{ THIO b } & \multirow{2}{*}{ Atoms } & \multicolumn{5}{|c|}{ THIO c } \\
\hline & $\mathbf{q N}$ & $f^{+}$ & $f^{-}$ & $S^{+}$ & $S^{-}$ & & $q_{N}$ & $f^{+}$ & $f^{-}$ & $S^{+}$ & $S^{-}$ & & qN & $f^{+}$ & $f^{-}$ & $S^{+}$ & $S^{-}$ \\
\hline $1 \mathrm{C}$ & -0.15 & 0.05 & -0.09 & 0.02 & -0.04 & $1 \mathrm{C}$ & -0.09 & -0.01 & -0.03 & 0.00 & -0.01 & $1 \mathrm{C}$ & -0.12 & 0.01 & 0.02 & 0 & 0.01 \\
\hline $2 \mathrm{C}$ & 0.23 & 0.04 & -0.03 & 0.02 & -0.02 & $2 \mathrm{C}$ & 0.21 & 0.06 & -0.05 & 0.03 & -0.02 & $2 \mathrm{C}$ & -0.15 & 0.03 & -0.01 & 0.01 & 0 \\
\hline $3 \mathrm{C}$ & -0.18 & 0.09 & -0.11 & 0.04 & -0.05 & $3 \mathrm{C}$ & -0.10 & 0.01 & -0.03 & 0.00 & -0.01 & $3 \mathrm{C}$ & 0.28 & 0.02 & -0.01 & 0.01 & 0 \\
\hline $4 \mathrm{C}$ & -0.19 & 0.05 & -0.08 & 0.02 & -0.04 & $4 \mathrm{C}$ & -0.14 & 0.00 & -0.03 & 0.00 & O 01 & $4 \mathrm{C}$ & -0.09 & 0.04 & 0.03 & 0.02 & 0.01 \\
\hline $5 \mathrm{C}$ & -0.18 & 0.30 & -0.32 & 0.15 & -0.16 & $5 \mathrm{C}$ & 0.13 & -0.01 & -0.01 & 0.00 & 0.00 & $5 \mathrm{C}$ & -0.1 & 0 & 0.01 & 0 & 0 \\
\hline $6 \mathrm{C}$ & -0.19 & 0.06 & -0.08 & 0.03 & -0.04 & $6 \mathrm{C}$ & -0.13 & 0.00 & -0.02 & 0.00 & -0.01 & $6 \mathrm{C}$ & -0.08 & 0.03 & 0.02 & 0.01 & 0.01 \\
\hline $11 \mathrm{~N}$ & -0.68 & 0.09 & -0.17 & 0.04 & -0.08 & $11 \mathrm{~N}$ & -0.52 & -0.07 & -0.01 & -0.03 & 0.00 & $11 \mathrm{~N}$ & -0.51 & 0.04 & 0.06 & 0.02 & 0.03 \\
\hline $14 \mathrm{C}$ & 0.38 & -0.07 & 0.06 & -0.04 & 0.03 & $14 \mathrm{C}$ & 0.31 & 0.00 & -0.01 & 0.00 & 0.00 & $14 \mathrm{C}$ & 0.28 & 0.01 & 0 & 0 & 0 \\
\hline $17 \mathrm{~S}$ & 0.16 & -0.35 & -0.03 & -0.17 & -0.01 & $15 \mathrm{~N}$ & -0.50 & 0.31 & -0.69 & 0.15 & -0.34 & $15 \mathrm{~N}$ & -0.51 & 0.04 & 0.06 & 0.02 & 0.03 \\
\hline $18 \mathrm{~S}$ & 0.16 & -0.35 & -0.01 & -0.17 & 0.00 & $12 \mathrm{C}$ & 0.31 & -0.50 & 0.14 & -0.25 & 0.07 & $12 \mathrm{C}$ & 0.28 & 0.01 & 0 & 0 & 0 \\
\hline $12 \mathrm{C}$ & 0.36 & -0.05 & 0.05 & -0.02 & 0.02 & $18 \mathrm{~S}$ & 0.09 & 0.22 & -0.22 & 0.11 & -0.11 & $18 \mathrm{~S}$ & 0.23 & 0.12 & 0.15 & 0.06 & 0.07 \\
\hline $15 \mathrm{~N}$ & -0.73 & 0.24 & -0.27 & 0.12 & -0.13 & $17 \mathrm{~S}$ & 0.09 & -0.58 & 0.55 & -0.28 & 0.27 & $17 \mathrm{~S}$ & 0.23 & 0.12 & 0.15 & 0.06 & 0.07 \\
\hline $16 \mathrm{~N}$ & -0.68 & 0.09 & -0.17 & 0.04 & -0.08 & $16 \mathrm{~N}$ & -0.52 & -0.07 & -0.01 & -0.03 & 0.00 & $16 \mathrm{~N}$ & -0.46 & 0.04 & 0.05 & 0.02 & 0.02 \\
\hline $23 \mathrm{C}$ & 0.23 & 0.04 & -0.01 & 0.02 & 0.00 & $23 \mathrm{C}$ & 0.22 & 0.05 & -0.02 & 0.02 & -0.01 & $23 \mathrm{C}$ & 0.1 & 0 & -0.04 & 0 & -0.02 \\
\hline $24 \mathrm{C}$ & -0.15 & 0.05 & -0.08 & 0.02 & -0.04 & $24 \mathrm{C}$ & -0.09 & -0.01 & -0.02 & 0.00 & -0.01 & $24 \mathrm{C}$ & 0.29 & 0.04 & 0.04 & 0.02 & 0.02 \\
\hline $19 \mathrm{C}$ & -0.19 & 0.10 & -0.10 & 0.05 & -0.05 & $11 \mathrm{C}$ & -0.09 & 0.00 & 0.00 & 0.00 & 0.00 & $11 \mathrm{C}$ & -0.13 & 0.01 & 0.01 & 0 & 0 \\
\hline $20 \mathrm{C}$ & -0.18 & 0.08 & -0.12 & 0.04 & -0.06 & $20 \mathrm{C}$ & -0.08 & -0.02 & -0.02 & -0.01 & -0.01 & $20 \mathrm{C}$ & -0.08 & 0.02 & 0.04 & 0.01 & 0.02 \\
\hline
\end{tabular}




\begin{tabular}{|c|c|c|c|c|c|c|c|c|c|c|c|c|c|c|c|c|c|}
\hline \multirow{2}{*}{ Atoms } & \multicolumn{5}{|c|}{ THIO a } & \multirow{2}{*}{ Atoms } & \multicolumn{5}{|c|}{ THIO b } & \multirow{2}{*}{ Atoms } & \multicolumn{5}{|c|}{ THIO c } \\
\hline & qN & $f^{+}$ & $f^{-}$ & $S^{+}$ & $S^{-}$ & & qN & $f^{+}$ & $f^{-}$ & $S^{+}$ & $S^{-}$ & & qN & $f^{+}$ & $f^{-}$ & $S^{+}$ & $S^{-}$ \\
\hline $21 \mathrm{C}$ & -0.19 & 0.09 & -0.10 & 0.04 & -0.05 & $21 \mathrm{C}$ & -0.10 & 0.00 & -0.01 & 0.00 & 0.00 & $21 \mathrm{C}$ & -0.1 & 0.01 & -0.01 & 0 & 0 \\
\hline $22 \mathrm{C}$ & -0.18 & 0.09 & -0.08 & 0.04 & -0.04 & $22 \mathrm{C}$ & 0.10 & -0.19 & 0.20 & -0.09 & 0.10 & $22 \mathrm{C}$ & -0.14 & 0.03 & 0.02 & 0.01 & 0.01 \\
\hline- & - & - & - & - & - & $30 \mathrm{C}$ & -0.40 & 0.02 & -0.01 & 0.01 & 0.00 & 190 & -0.52 & 0.03 & 0.01 & 0.01 & 0 \\
\hline- & - & - & - & - & - & - & - & - & - & - & - & $20 \mathrm{C}$ & 0.11 & 0.02 & 0.1 & 0.01 & 0.05 \\
\hline
\end{tabular}

Table 10. Mulliken charge density and Fukui indices for the atoms present in thiourea series.

\begin{tabular}{|c|c|c|c|c|c|c|c|c|c|c|c|c|c|c|c|c|c|}
\hline \multirow{2}{*}{ Atoms } & \multicolumn{5}{|c|}{ THIO a } & \multirow{2}{*}{ Atoms } & \multicolumn{5}{|c|}{ THIO b } & \multirow{2}{*}{ Atoms } & \multicolumn{5}{|c|}{ THIO c } \\
\hline & $q_{N}$ & $f^{+}$ & $f^{-}$ & $S^{+}$ & $S^{-}$ & & $\mathbf{q N}$ & $f^{+}$ & $f^{-}$ & $S^{+}$ & $S^{-}$ & & qN & $f^{+}$ & $f^{-}$ & $S^{+}$ & $S^{-}$ \\
\hline $1 \mathrm{C}$ & -0.11 & -0.01 & 0.00 & 0.00 & 0.00 & $1 \mathrm{C}$ & -0.1 & 0 & 0 & 0 & 0 & $1 \mathrm{C}$ & -0.17 & 0 & 0.03 & 0 & 0.01 \\
\hline $2 \mathrm{C}$ & 0.27 & 0.04 & 0.01 & 0.02 & 0.00 & $2 \mathrm{C}$ & 0.26 & 0.05 & 0.01 & 0.02 & 0 & $2 \mathrm{C}$ & 0.24 & 0.12 & 0 & 0.06 & 0 \\
\hline $3 \mathrm{C}$ & -0.12 & 0.03 & 0.06 & 0.01 & 0.03 & $3 \mathrm{C}$ & -0.12 & 0.03 & 0.07 & 0.01 & 0.03 & $3 \mathrm{C}$ & -0.2 & 0.03 & 0.13 & 0.01 & 0.06 \\
\hline $4 \mathrm{C}$ & 0.10 & -0.19 & 0.19 & -0.09 & 0.09 & $4 \mathrm{C}$ & -0.13 & 0.02 & 0.01 & 0.01 & 0 & $4 \mathrm{C}$ & -0.2 & 0.04 & 0.03 & 0.02 & 0.01 \\
\hline $5 \mathrm{C}$ & -0.08 & 0.02 & 0.05 & 0.01 & 0.02 & $5 \mathrm{C}$ & 0.13 & 0.01 & 0.02 & 0 & 0.01 & $5 \mathrm{C}$ & 0.32 & 0.05 & 0.1 & 0.02 & 0.05 \\
\hline $6 \mathrm{C}$ & -0.09 & 0.01 & 0.02 & 0.00 & 0.01 & $6 \mathrm{C}$ & -0.13 & 0.03 & 0.03 & 0.01 & 0.01 & $6 \mathrm{C}$ & -0.22 & 0.03 & 0.04 & 0.01 & 0.02 \\
\hline $12 \mathrm{~N}$ & -0.57 & 0.00 & -0.02 & 0.00 & -0.01 & $11 \mathrm{~N}$ & -0.57 & 0.04 & -0.02 & 0.02 & -0.01 & $11 \mathrm{~N}$ & -0.78 & -0.01 & -0.02 & -0.01 & -0.01 \\
\hline $15 \mathrm{C}$ & 0.32 & 0.03 & 0.09 & 0.01 & 0.04 & $14 \mathrm{C}$ & 0.32 & -0.03 & 0.08 & -0.01 & 0.04 & $14 \mathrm{C}$ & 0.23 & 0 & -0.01 & 0 & -0.01 \\
\hline $13 \mathrm{~N}$ & -0.58 & 0.02 & 0.02 & 0.01 & 0.01 & $12 \mathrm{~N}$ & -0.58 & 0.03 & 0.01 & 0.01 & 0 & $12 \mathrm{~N}$ & -0.73 & 0.02 & 0.01 & 0.01 & 0 \\
\hline $14 \mathrm{~S}$ & -0.31 & 0.57 & 0.25 & 0.28 & 0.12 & $13 \mathrm{~S}$ & -0.32 & 0.39 & 0.23 & 0.19 & 0.11 & $13 \mathrm{~S}$ & -0.1 & 0.33 & 0.21 & 0.16 & 0.1 \\
\hline- & - & - & - & - & - & $18 \mathrm{C}$ & -0.38 & -0.02 & -0.01 & -0.01 & 0 & 180 & -0.55 & 0.04 & -0.01 & 0.02 & -0.01 \\
\hline- & - & - & - & - & - & - & - & - & - & - & - & $19 \mathrm{C}$ & -0.34 & -0.04 & -0.03 & -0.02 & -0.01 \\
\hline
\end{tabular}


Table 11. Theoretically calculated inhibition efficiency for the studied compounds.

\begin{tabular}{|c|c|c|c|c|}
\hline \multirow{2}{*}{ Inhibitor } & \multirow{2}{*}{$I_{\text {add }} \%$} & \multirow{2}{*}{$I E_{\text {add }} \%$} & \multicolumn{2}{|c|}{ Inhibition efficiency $\%$} \\
\hline & & & Theoretical & Experimental \\
\hline \multicolumn{5}{|c|}{ Diathiazolidine derivatives } \\
\hline DTA a & - & - & 98.90 & 98.9 \\
\hline DTA b & +1.23 & +0.01 & 99.00 & 99.4 \\
\hline DTA c & +3.82 & +1.61 & 99.61 & 99.6 \\
\hline \multicolumn{5}{|c|}{ Thioamidine derivatives } \\
\hline TAD a & - & - & 95.10 & 95.1 \\
\hline TAD b & +6.30 & +3.01 & 98.11 & 98.1 \\
\hline TAD c & +7.20 & +3.82 & 98.91 & 99.1 \\
\hline \multicolumn{5}{|c|}{ Thiourea derivatives } \\
\hline THIO a & - & - & 93.0 & 93.0 \\
\hline THIO b & +5.87 & +2.99 & 95.99 & 96.2 \\
\hline THIO c & +7.03 & +4.53 & 97.53 & 99.1 \\
\hline
\end{tabular}

\section{References}

1. B.K. Sen, Quantum Chemistry Including Molecular Spectroscopy, Tata McGraw-Hill, Publishing Company Ltd., New Delhi, 1996.

2. A.K. Chandra, Introductory Quantum Chemistry, Tata McGraw Hill Publishing Company Ltd., New Delhi, 1998.

3. A.S. Negi and S.C. Anand, A Text Book of Physical Chemistry, New Age International (P) Ltd., New Delhi, 2002.

4. R.K. Prasad, Quantum Chemistry, New Age International (P) Ltd., New Delhi, 2003.

5. S.K. Dogra and S. Dogra, Physical Chemistry through Problems, Wiley Eastern Ltd., New Delhi, 2001.

6. J.B. Frishman and A. Frisel, Exploring Chemistry with Electronic Structure Methods, 3rd ed., Gaussian, Inc., Wallingford, CT, 2015.

7. J.B. Foresman, Ab Initio Techniques in Chemistry: Interpretation and Visualization, Chapter 14 in "What Every Chemist Should Know about Computing", Ed. M.L. Swift and T.J. Zielinski, ACS Books, Washington, D.C., 1996.

8. A. Szabo and N.S. Ostlund, Modern Quantum Chemistry, McGraw-Hill, New York, 1982.

9. W.J. Hehre, L. Radom, P.V.R. Schleyer and J.A. Pople, Ab Initio Molecular Orbital theory, Wiley, New York, 1986. 
10. M.M. Kabanda, S.K. Shukla, A.K. Singh, L.C. Murulana and E.E. Ebenso, Electrochemical and quantum chemical studies on Calmagite and Fast Sulphone Black $\mathrm{F}$ dyes as Corrosion Inhibitors for mild steel in hydrochloric medium, Int. J. Electrochem. Sci., 2012, 7, 8813-8831.

11. O.Y. Ayse, D.M. Basak, G. Kardas and B. Yazici, Electrochemical and quantumchemical studies of 2-amino-4-methyl-thiazole as corrosion inhibitor for mild steel in $\mathrm{HCl}$ solution, Corros. Sci., 2014, 83, 310-316. doi: 10.1016/j.corsci.2014.02.029

12. H.H.A. Rahman, A.H.E. Moustafa and M.K. Awad, Potentiodynamic and quantum studies of some amino acids as corrosion inhibitors for copper, Int. J. Electrochem. Sci., 2012 7, 1266-1287.

13. G. Gece, The use of quantum chemical methods in corrosion inhibitor studies, Corros. Sci., 2008, 50, 2981-2992. doi: 10.1016/j.corsci.2008.08.043

14. N.O. Eddy and E.E. Ebenso, Adsorption and quantum chemical studies on Cloxacillin and halides for the corrosion of mild steel in acidic medium, Int. J. Electrochem. Sci., 2010, 5, 731-750.

15. S. Junaedi, A.A. Al-Amiery, A. Kadihum, A.A.H. Kadhum and A.B. Mohamad, Inhibition effects of a synthesized novel 4-aminoantipyrine derivative on the corrosion of mild steel in hydrochloric acid solution together with quantum chemical studies, Int. J. Mol. Sci., 2013, 14, 11915-11928. doi: 10.3390/ijms140611915

16. L.C. Murulana, A.K. Singh, S.K. Shukla, M.M. Kabanda and E.E. Ebenso, Experimental and quantum chemical studies of some Bis(trifluoromethyl-sulfonyl) imide Imidazolium-based ionic liquids as corrosion inhibitors for mild steel in hydrochloric acid solution, Ind. Eng. Chem. Res., 2012, 51, 13282-13299. doi: $\underline{10.1021 / i e 300977 \mathrm{~d}}$

17. D. Nalini, D. Sudha and S. Ramkumar, Corrosion inhibition of Indoloimidazole derivative on mild steel in $\mathrm{HCl}$, Chem. Sci. Rev. Lett., 2013, 2, 323-331.

18. N.O. Eddy, B.I. Ita, N.E. Ibisi and E.E. Ebenso, Experimental and quantum chemical studies on the corrosion inhibition potentials of 2-(2-oxoindolin-3-ylideneamino) acetic acid and indoline-2,3-dione, Int. J. Electrochem. Sci., 2011, 6, 1027-1044.

19. A. Singh, E.E. Ebenso, M.A. Quraishi, Theoretical and electrochemical studies of Metformin as corrosion inhibitor for mild steel in hydrochloric acid solution, Int. J. Electrochem. Sci., 2012, 7, 4766-4779.

20. D. Wahyuningrum, S. Achmad, Y.M. Syah, Buchari and B. Ariwahjoedi, The Synthesis of Imidazoline derivative compounds as corrosion inhibitor towards carbon steel in $1 \%$ $\mathrm{NaCl}$ solution, 2008, 40, 33-48. doi: 10.5614/itbj.sci.2008.40.1.4

21. H. Vashisht, S. Kumar, I. Bahadur and G. Singh, Evaluation of (2-hydroxyethyl) triphenyl phosphonium bromide as corrosion inhibitor for mild steel in sulphuric acid, Int. J. Electrochem. Sci., 2031, 8, 684-699. 
22. M.J. Momeni, H. Behzadi, P. Roonasi, S.A.S. Sadjadi, S.M. Mousavi-Khoshdel, S.V. Mousavi, Ab initio study of two Quinoline derivatives as corrosion inhibitor in acidic media: Electronic structure, inhibitor-metal interaction, and nuclear quadrupole resonance parameters, Res. Chem. Intermed., 2015, 41, 6789-6802. doi: 10.1007/s11164-014-1777-4

23. M.M. Kabanda, L.C. Murulana, M. Ozcan, and F. Karadag, Quantum chemical studies on the corrosion inhibition of mild steel by some Triazoles and Benzimidazole derivatives in acidic medium, Int. J. Electrochem. Sci., 2012, 7, 5035-5056.

24. S. Ramkumar and D. Nalini, Correlation between inhibition efficiency and chemical structure of new Indoloimidazoline on the corrosion of mild steel in molar $\mathrm{HCl}$ with DFT evidences, Orient. J. Chem., 2015, 31, 1057-1064. doi: 10.13005/ojc/310255

25. Z. Cao, Y. Tang, H. Cang, J. Xu, G. Lu and W. Jing, Novel Benzimidazole derivatives as corrosion inhibitors of mild steel in the acidic media. Part II: Theoretical studies, Corros. Sci., 2014, 83, 292-298. doi: 10.1016/j.corsci.2014.02.025

26. S. John and A. Joseph, Theoretical and electrochemical studies on the effect of substitution on 1,2,4-Triazole towards mild steel corrosion inhibition in hydrochloric acid, Int. J. Chem. Technol., 2012, 19, 195-204.

27. N. Patel and D. Šnita, Ethanol extracts of Hemidesmus indicus leaves as eco-friendly inhibitor of mild steel corrosion in $\mathrm{H}_{2} \mathrm{SO}_{4}$ medium, Chem. Pap., 2014, 68, 1747-1754. doi: $10.2478 / \mathrm{s} 11696-014-0625-8$

28. M. Bello, N. Ochoa, V. Balsamo, F. López-Carrasquero, S. Coll, A. Monsalve and G. González, Modified cassava starches as corrosion inhibitors of carbon steel: An electrochemical and morphological approach, Carbohydr. Polym., 2010, 82, 561-568. doi: $10.1016 /$ j.carbpol.2010.05.019

29. B. Miehlich, A. Savin, H. Stoll and H. Preuss, Results obtained with the correlationenergy density functionals of Becke and Lee, Yang and Parr, Chem. Phys. Lett., 1989, 157, 200-206. doi: 10.1016/0009-2614(89)87234-3

30. M.R.N. El-Din and E.A. Khamis, Corrosion inhibition efficiency, electrochemical and quantum chemical studies of some new nonionic Surfactants for carbon steel in acidic media, J. Surfactants Deterg., 2014, 17, 795-805. doi: 10.1007/s11743-014-1565-6

31. M.A. Surati, S. Jauhari and K.R. Desai, A Brief Review: Microwave Assisted Organic Reaction, Arch. Appl. Sci. Res., 2012, 4, 645-661.

32. S. Kumar, D. Sharma, P. Yadav and M. Yadav, Experimental and quantum chemical studies on corrosion inhibition effect of synthesized organic compounds on N80 steel in hydrochloric acid, Ind. Eng. Chem. Res., 2013, 52, 14019-14029. doi: 10.1021/ie401308v

33. S. Junaedi, A.A.H. Kadhum, A.A. Al-amiery and A.B. Mohamad, Synthesis and characterization of novel corrosion inhibitor derived from oleic acid: 2-amino-5- oleyl1,3,4-thiadiazol (AOT), Int. J. Electrochem. Sci., 2012, 7, 3543-3554. 
34. D. Nalini, K.S. Kohilah and S. Ramkumar, A combined experimental and theoretical investigation on Pyrazolone derivative as corrosion inhibitor for mild steel in $0.5 \mathrm{M}$ sulphuric acid media, Port. Electrochim. Acta, 2014, 32, 109-123. doi: 10.4152/pea.201402109

35. M. Yadav, D. Behera, S. Kumar and R.R. Sinha, Experimental and quantum chemical studies on the corrosion inhibition performance of Benzimidazole derivatives for mild steel in HCl, Ind. Eng. Chem. Res., 2013, 52, 6318-6328. doi: 10.1021/ie400099q

36. S. Chen and T. Kar, Theoretical investigation of inhibition efficiencies of some Schiff bases as corrosion inhibitors of aluminum, Int. J. Electrochem. Sci., 2012, 7, $6265-6275$.

37. K. Ramya, R. Mohan and A. Joseph, Interaction of Benzimidazoles and Benzotriazole:Its corrosion protection properties on mild steel in hydrochloric acid, $J$. Mater. Eng. Perform., 2014, 23, 4089-4101. doi: 10.1007/s11665-014-1183-5

38. A. Singh, A.K. Singh and M.A. Quraishi, Dapsone: A novel corrosion inhibitor for mild steel in acid media, Open Electrochem. J., 2010, 2, 43-51. doi: $\underline{10.2174 / 1876505 X 01002010043}$

39. B.S. Shylesha, T.V. Venkatesha and B.M. Praveen, Corrosion inhibition studies of mild steel by new inhibitor in different corrosive medium, Res. J. Chem. Sci., 2011, 1, 46-50.

40. M. Pitchaipillai, K. Raj, J. Balasubramanian, and P. Periakaruppan, Benevolent behavior of Kleinia grandiflora leaf extract as a green corrosion inhibitor for mild steel in sulfuric acid solution, Int. J. Miner. Metall. Mater., 2014, 21, 1083-1095. doi: 10.1007/s12613-014-1013-7

41. K. Shalabi, Y.M. Abdallah and A.S. Fouda, Corrosion inhibition of aluminum in $0.5 \mathrm{M}$ $\mathrm{HCl}$ solutions containing Phenylsulfonylacetophenoneazo derivatives, Res. Chem. Intermed., 2014, 41, 4687-4711. doi: 10.1007/s11164-014-1561-5

42. K.F. Khaled and M.A. Amin, Dry and wet lab studies for some Benzotriazole derivatives as possible corrosion inhibitors for copper in $1.0 \mathrm{M} \mathrm{HNO}_{3}$, Corros. Sci., 2009, 51, 2098 2106. doi: 10.1016/j.corsci.2009.05.038

43. M.A. Chidiebere, C.E. Ogukwe, K.L. Oguzie, C.N. Eneh and E.E. Oguzie, Corrosion inhibition and adsorption behavior of Punica granatum extract on mild steel in acidic environments: Experimental and theoretical studies, Ind. Eng. Chem. Res., 2012, 5, 668677. doi: $10.1021 / \mathrm{ie} 201941 \mathrm{f}$

44. J. Fu, H. Zang, Y. Wang, S. Li, T. Chen, and X. Liu, Experimental and theoretical study on the inhibition performances of Quinoxaline and its derivatives for the corrosion of mild steel in hydrochloric acid, Ind. Eng. Chem. Res., 2012, 51, 6377-6386. doi: 10.1021/ie202832e

45. L. Larabi, O. Benali, S.M. Mekelleche and Y. Harek, 2-Mercapto-1-methylimidazole as corrosion inhibitor for copper in hydrochloric acid, Appl. Surf. Sci., 2006, 253, 13711378. doi: $\underline{10.1016 / j . a p s u s c .2006 .02 .013}$ 
46. F. Bentiss, C. Jama, B. Mernari, H. El, L. El, M. Lebrini, M. Traisnel and M. Lagrenée, Corrosion control of mild steel using 3,5-bis(4-methoxyphenyl)-4-amino- 1,2,4-triazole in normal hydrochloric acid medium, Corros. Sci., 2009, 51, 1628-1635. doi: 10.1016/j.corsci.2009.04.009

47. H.R. Obayes, G.H. Alwan, A.H.M. Alobaidy, A.A. Al-Amiery, A.A.H. Kadhum, and A.B. Mohamad, Quantum chemical assessment of Benzimidazole derivatives as corrosion inhibitors., Chem. Cent. J., 2014, 8, 21. doi: 10.1186/1752-153X-8-21

48. A.A.M. Prabhu, G. Venkatesh, R.K. Sankaranarayanan, S. Siva and N. Rajendiran, Azonium-ammonium tautomerism and inclusion complexation of 4-amino-2', 3dimethylazobenzene, Indian J. Chem. Sect. A, 2010, 49, 407-417.

49. Y.M. Tang, W.Z. Yang, X.S. Yin, Y. Liu, R. Wan and J.T. Wang, Phenyl-Substituted Amino Thiadiazoles as Corrosion Inhibitors for Copper in $0.5 \mathrm{M} \mathrm{H}_{2} \mathrm{SO}_{4}$, Mater. Chem. Phys. 2009, 116, 479-483. doi: 10.1016/j.matchemphys.2009.04.018

50. W. Gong, X. Yin, Y. Liu, Y. Chen and W. Yang, 2-Amino-4-(4-Methoxyphenyl)Thiazole as a Novel Corrosion Inhibitor for Mild Steel in Acidic Medium, Prog. Org. Coatings, 2019, 126, 150-161. doi: 10.1016/j.porgcoat.2018.10.001

51. C.I. Yeo and E.R.T. Tiekink, 1-[n-Methyl-n-(Phenyl)Amino]-3-(4-Methylphenyl) Thiourea, Molbank, 2019, 2019, 1-5. doi: 10.3390/M1052

52. M. Mushtaque, M. Jahan, M. Ali, M.S. Khan, M.S. Khan,P. Sahay and A. Kesarwani, Synthesis, characterization, molecular docking, DNA binding, cytotoxicity and DFT studies of 1-(4-methoxyphenyl)-3-(pyridine-3-ylmethyl)thiourea. J. Mol. Struct. 2016, 1122, 164-174. doi: 10.1016/j.molstruc.2016.05.087

53. A. Tadjarodi, F. Adhami, Y. Hanifehpour, M. Yazdi, Structural Characterization of a Copper (II) Complex Containing New Ligands of 4-Picolylthiourea Derivatives and the Precursor Molecular Structure of Oxidative Cyclization of N-(2-pyridyl)-N'-(4methoxyphenyl)thiourea, Polyhedorn, 2007, 26, 4609-4618. doi: 10.1016/i.poly.2007.06.014

54. J.R. Xavier, S. Nanjundan and N. Rajendran, Electrochemical Adsorption Properties and Inhibition of Brass Corrosion in Natural Seawater by Thiadiazole Derivatives: Experimental and Theoretical Investigation, Ind. Eng. Chem. Res., 2012, 51, 30-43. doi: 10.1021/ie1016464

55. M. Yadav, D. Behera, S. Kumar and P. Yadav, Experimental and Quantum Chemical Studies on Corrosion Inhibition Performance of Thiazolidinedione Derivatives for Mild Steel in Hydrochloric Acid Solution, Chem. Eng. Commun., 2015, 202, 303-315. doi: 10.1080/00986445.2013.841148

56. A.E.E. Fouda and A. Hussein, Role of Some Phenylthiourea Derivatives as Corrosion Inhibitors for Carbon Steel in HCl Solution, J. Korean Chem. Soc., 2012, 56, 264-273. doi: $10.5012 / \mathrm{jkcs} .2012 .56 .2 .264$ 